\title{
A ATIVIDADE COMO SUPORTE PARA PROJETO DE LAYOUT DE UM SISTEMA PRODUTIVO
}

\section{THE ACTIVITY AS SUPPORT FOR THE DESIGN OF PRODUCTIVE SYSTEM LAYOUT}

\author{
Mayara Ramos ${ }^{1}$, M.Sc \\ Fernanda Gomes Faust ${ }^{2}$, M.Sc \\ Leila Amaral Gontijo ${ }^{3}$ D.Sc \\ Marcelo Gitirana Gomes Ferreira ${ }^{4}$ D.Sc \\ (1) Universidade Federal de Santa Catarina (UFSC) \\ e-mail: mayara.ramos@gmail.com \\ (2) Universidade Federal de Santa Catarina (UFSC) \\ e-mail: fernandagfaust@gmail.com \\ (3) Universidade Federal de Santa Catarina (UFSC) \\ e-mail: leila.gontijo@ufsc.br \\ (3) Universidade do Estado de Santa Catarina (UDESC) \\ e-mail: marcelo.gitirana@gmail.com
}

\begin{abstract}
Palavras-chave: análise ergonômica do trabalho, produtividade, layout
A ergonomia influencia diretamente a produtividade, pois melhores condições do posto de trabalho resultam em trabalhadores mais produtivos. Neste trabalho, por meio de uma AET, foram analisados os deslocamentos realizados no setor de montagem de uma fábrica, e como o layout e os deslocamentos influenciam na sua produtividade. Na montagem de um equipamento os deslocamentos são referentes a aproximadamente $35 \%$ do tempo de montagem. Em uma proposta de novo layout para o setor, a simulação dos deslocamentos demonstrou uma redução média de $75.25 \%$ na montagem de equipamentos.
\end{abstract}

Key-words: ergonomic work analysis, productivity, layout

Ergonomics have a direct influence on productivity, better work station conditions result in more productive workers. Through an ergonomic work analysis, this paper analyzed trajectory movements made in the assembly department of a factory, and how the department layout and the movements reflect on its productivity. On one equipment assembly, the trajectory movements correspond to 35\% of the assembly time. A new layout was proposed, and the simulation for the trajectory showed an average reduction of $75,25 \%$ on equipment assembly.

\section{Introdução}

A primeira finalidade da ação ergonômica é a transformação do trabalho. Essa transformação deve ser realizada para contribuir na concepção de situações de trabalho que não alterem a saúde dos operadores e alcançar os objetivos econômicos determinados pela empresa, em função dos investimentos realizados ou futuros (GUÉRIN et al., 2001).

A análise de uma situação de trabalho pressupõe um conhecimento global do processo de produção, visando atingir uma melhor compreensão das relações que existem entre o trabalho específico de um setor e o realizado pelo conjunto da empresa. A análise permite localizar as exigências globais de qualidade que podem impor constrangimentos específicos à realização de certas atividades (GUÉRIN et al., 2001). Para a ergonomia, o aperfeiçoamento do sistema homem-máquinaambiente, pode ocorrer tanto na fase de projeto (máquinas, equipamentos e postos de trabalho), como na introdução de modificações em sistemas já existentes, adaptando-os às capacidades e limitações do organismo humano (IIDA, 2005).

No projeto de postos de trabalhos industriais a principal preocupação é na melhoria do desempenho dos equipamentos, se tem pouca consideração em 
combinar as habilidades do operador com os requisitos da tarefa. Como consequência, os postos de trabalho das indústrias são mal projetados (DAS; SENGUPTA, 1996). Ao não observar a ergonomia do processo, as condições de trabalho resultam em perda de produtividade dos trabalhadores e produção final além de afetar a saúde do trabalhador (DAS; SENGUPTA, 1996; FIEDLER et al., 2009). Nestas situações, comumente ocorrem fadigas, posturas inadequadas gerando dores no sistema musculoesquelético do trabalhador, também ocasionando a redução do ritmo de trabalho e de raciocínio, o que pode levar a erros e ao seu afastamento por doenças ocupacionais (FIEDLER et al., 2009). Uma maneira de minimizar esses problemas é a formação de um layout ótimo para o trabalho (FIEDLER et al., 2009; SHINDE; JADHAV, 2012).

Para a melhoria da produtividade nas indústrias de manufatura, a eficiência do trabalhador é um fator importante. A produtividade do trabalhador depende do projeto ergonômico do posto de trabalho (SHINDE; JADHAV, 2012). A ergonomia não se limita à prevenção e eliminação de lesões de trabalho, ela pode também ser usada para auxiliar no aumento da produtividade. Trabalhadores fadigados estão mais propensos a lesões e tendem a diminuírem seu ritmo de trabalho (RESNICK; ZANOTTI, 1997). Uma abordagem ergonômica ao projeto de postos de trabalho industriais busca alcançar um equilíbrio entre as capacidades dos trabalhadores e os requisitos de trabalho para otimizar a produtividade do trabalhador e do sistema como um todo, assim como fornecer ao trabalhador bem-estar físico e mental, segurança e satisfação do trabalho (DAS; SENGUPTA, 1996).

A organização de um arranjo físico (ou layout) é fundamental para a melhoria da organização espacial, dos aspectos ergonômicos e do aumento da produtividade dentro de uma organização. O layout interfere em toda cadeia produtiva e pode trazer resultados positivos; layouts específicos podem contribuir na redução de desperdícios (SOTSEK; BONDUELLE, 2016).

O layout é o estudo da distribuição espacial ou do posicionamento relativo dos diversos elementos que compõe o posto de trabalho, ou seja, como serão posicionados os diversos instrumentos de informação e controle existentes no posto de trabalho (IIDA, 2005). Os procedimentos de layout determinam a forma de organizar o maquinário e departamentos para alcançar a minimização de tempo de produção, a maximização do volume de negócios e maximização da capacidade produtiva. A capacidade de reconfigurar um sistema de produção existente é um fator chave para manter competitividade no ambiente de negócios de produção (ROSA et al., 2014).

Desde 1930 vem se estudando o trabalho com o objetivo de descobrir métodos melhores e mais simples de se executar uma tarefa, nesse período os estudos de tempos e de movimentos foram usados conjuntamente, complementando um ao outro. A principal preocupação da área de estudo de movimentos e tempos é a definição de sistemas e métodos de trabalho, o objetivo é determinar o método ideal ou o que mais se aproxima do ideal para ser usado na prática. Os termos projeto de trabalho ou estudo de trabalho já foram sugeridos para serem usados em lugar de estudos de movimentos e tempos (BARNES, 1977).

Muitos trabalhos/projetos de Análise Ergonômica do Trabalho (AET) focam nos problemas advindos de esforços repetitivos, posturais e mobiliário. Neste artigo, no entanto, a demanda da AET foi um estudo focada na melhoria dos deslocamentos do setor de montagem. Por meio da avaliação das atividades do trabalho em comparação análise do fluxo de atividade constatou-se que as colaboradoras do setor realizavam deslocamentos excessivos e evitáveis, gerando a hipótese de que esses deslocamentos podem causar sobrecarga sob membros inferiores e sensação de improdutividade. O objetivo deste estudo é desenvolver a análise de deslocamentos para o setor de montagem avaliando a influência do layout na produtividade do setor.

\section{Método}

O estudo aqui apresentado foi realizado em uma empresa que atua na produção de equipamentos e acessórios de Pilates. Atualmente a empresa está localizada em São José, Santa Catarina, cidade pertencente à Grande Florianópolis. A empresa está no mercado há 4 anos e conta com 36 pessoas no seu quadro de funcionários. A AET foi realizada no setor de montagem desta empresa. A Figura 1 mostra a organização dos setores da empresa destacando o setor de montagem. 


\section{Ergodesign \& HCI}

número especial, volume 5 , ano 5 (2017) ISNN 2317-8876, Rio de Janeiro - Brasil
PUC-Rio Pontifícia Universidade Católica do Rio de Janeiro Departamento de Artes \& Design | PPGDesign

LEUI | Laboratório de Ergodesign e Usabilidade de Interfaces

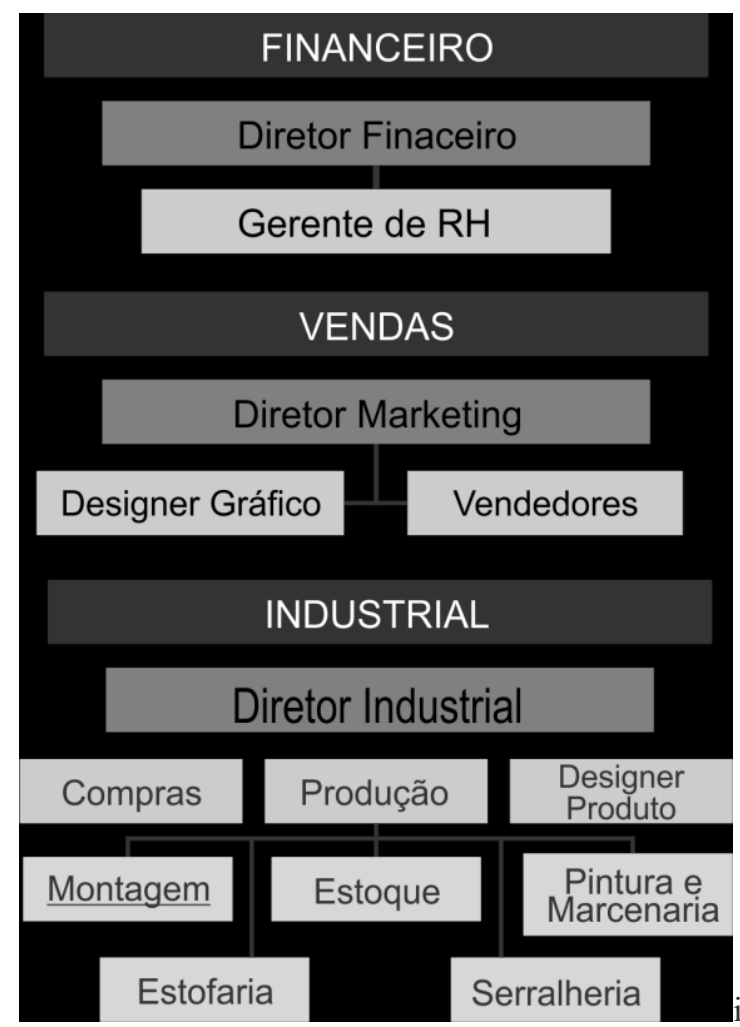

Figura 1: Organograma institucional da empresa estudada.

Trabalham no setor duas montadoras (26 e 41 anos de idade), que efetuam a montagem dos equipamentos, seus subitens e embalagem final dos produtos. Também trabalha no setor uma supervisora de montagem (33 anos) que organiza a montagem e verifica a montagem adequada quando acontece algo fora do normal

Para projetar um posto de trabalho industrial, neste caso linha de montagem, Das e Sengupta (1996), colocam a necessidade de obter informações relevantes ou dados do desempenho da tarefa, equipamentos, posturas de trabalho e ambiente. No caso de modificações, informações dos usuários ou operadores podem ser úteis para reforçar as recomendações feitas para melhoria do projeto do posto de trabalho/layout baseado em dados e princípios ergonômicos.

Afim de se obter informações relevantes e dados do desempenho da tarefa, foram coletados dados através da análise da tarefa utilizando-se métodos diretos tais como a observação direta dos pesquisadores no setor, realização de entrevistas semiestruturadas e aplicação de questionário Nórdico. Dos métodos indiretos foram utilizadas 3 câmeras de gravação de vídeo direcionadas ao setor a fim de obter informações de tempo, erros, posturas, comentário a serem questionados durante a observação.

Com as observações dos vídeos, foram mapeadas as atividades realizadas nas montagens, e feita a análise de tempos e deslocamentos das funcionárias para a montagem dos principais equipamentos do setor. A partir dessa análise se obteve a origem e os destinos dos deslocamentos bem como seus objetivos. Tendo assim um conhecimento completo sobre o processo de trabalho da montagem, sub-montagem e embalagem efetuadas pelas colaboradoras.

Foi também catalogado as medidas do mobiliário do setor, peso dos equipamentos, números de peças e componentes por equipamento.

Esse estudo avaliou os deslocamentos e tempos da montagem dos quatro produtos de maior volume de produção, sendo eles: Cadilac (CD), Reformer (RF), Ladder Barrel (LB) e Step Chair (SC); que são os equipamentos básicos de um estúdio de pilates. Foi estabelecido o processo de montagem desses equipamentos (por meio da análise da atividade e fluxo de atividades das duas montadoras), e foram estabelecidos os pontos básicos para a mensuração dos deslocamentos, e coletado o tempo de duração dos deslocamentos. Assim se estabeleceu o processo de montagem médio (existindo diferenças entre as montadoras). O layout do setor foi modelado no SolidWords ${ }^{\circledR}$, o que permitiu a visualização espacial do setor e gerar a planta/mapa do layout.

A mensuração dos deslocamentos foi realizada através do Adobe Illustrator ${ }^{\circledR}$ com o traçado dos deslocamentos definidos no processo na planta gerada pela modelagem. O tempo do processo de montagem se deu pela observação da duração dos deslocamentos, das principais operações de montagem e montagem de subitens. Com as distâncias dos deslocamentos e os tempos coletados, os dados foram catalogados e tabulados no Microsoft Excel gerando o deslocamento e tempo calculado para o processo de montagem dos equipamentos analisados.

Para o desenvolvimento de uma proposta de melhoria de layout, visando à melhoria da atividade de montagem minimizando os deslocamentos, foi avaliado o processo de montagem atual subtraindo os deslocamentos desnecessários. Os deslocamentos desta proposta foram simulados e mensurados da 


\section{Ergodesign \& HCI}

número especial, volume 5 , ano 5 (2017) ISNN 2317-8876, Rio de Janeiro - Brasil
PUC-Rio Pontifícia Universidade Católica do Rio de Janeiro Departamento de Artes \& Design | PPGDesign

LEUI | Laboratório de Ergodesign e Usabilidade de Interfaces mesma forma que o estado atual a fim de confirmar a otimização do processo.

\section{Análise de processo de montagem, atividades, tempos e deslocamento.}

O ambiente de trabalho do setor apresenta três bancadas para montagem, e três bancadas para a embalagem dos equipamentos, estas perto do local de expedição dos produtos. O setor apresenta vários estoques (peças, estofados, estruturas metálicas), gabaritos de montagem e prateleiras de armazenamento de equipamentos e outros materiais usados durante a montagem dos produtos. Os locais definidos para esses objetos não estão posicionados necessariamente perto do seu local de uso, gerando assim deslocamento para a realização das atividades de trabalho. A Figura 2 mostra o ambiente de trabalho do setor de montagem.

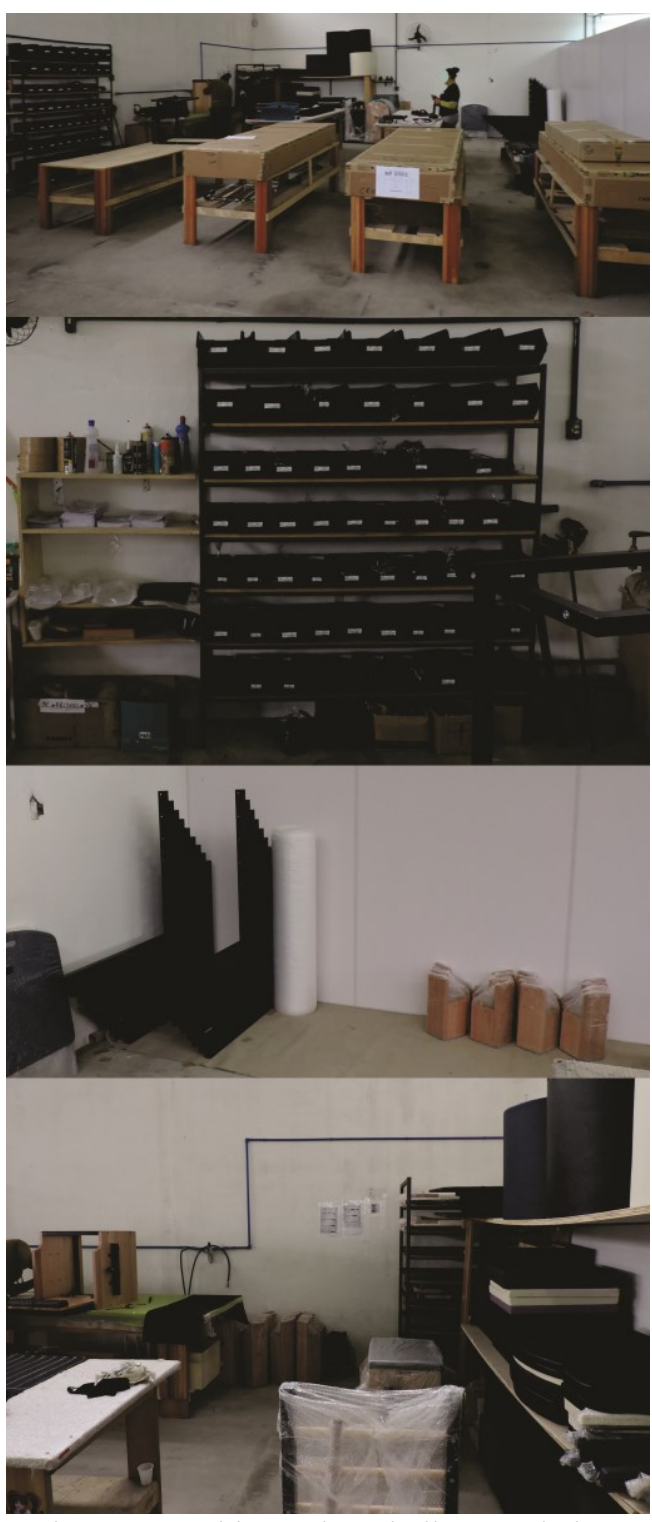

Figura 1: Ambiente de trabalho estudadoarmazenamento material de consumo, estoque metais, estoque estofados.

No processo de montagem dos equipamentos, as montadoras realizam deslocamentos carregando peças dos equipamentos do estaque até a bancada de montagem assim como subitens, como caixas de conjuntos de molas. Essas peças devido suas dimensões e materiais de composição tendem a ser pesados, o que pode gerar desconfortos as montadoras. A Tabela 1 mostra uma relação de peças e subitens presentes no processo de trabalho e seus pesos.

\begin{tabular}{|c|c|}
\hline Peça & Peso \\
\hline \multicolumn{2}{|c|}{ Cadilac } \\
\hline Madeiras & $18,3 \mathrm{Kg}$ \\
\hline Tubos Inox & 3 4Kg cada \\
\hline
\end{tabular}


Ergodesign \& HCI

número especial, volume 5 , ano 5 (2017) ISNN 2317-8876, Rio de Janeiro - Brasil
PUC-Rio Pontifícia Universidade Católica do Rio de Janeiro Departamento de Artes \& Design | PPGDesign

LEUI | Laboratório de Ergodesign e Usabilidade de Interfaces

\begin{tabular}{|l|c|}
\hline Caixas molas & $8 \mathrm{Kg}$ \\
\hline Caixa mancal & $13 \mathrm{Kg}$ \\
\hline \multicolumn{2}{|c|}{ Reformer } \\
\hline Madeiras & $15,5 \mathrm{Kg}$ \\
\hline Carrinho estofado & $9,5 \mathrm{Kg}$ \\
\hline Base carrinho & $9,2 \mathrm{Kg}$ \\
\hline Caixa subitens 1 & $6 \mathrm{Kg}$ \\
\hline Caixa subitens 2 & $2 \mathrm{Kg}$ \\
\hline \multicolumn{2}{|c|}{} \\
\hline Estrutura metálica & $10 \mathrm{Kg}$ \\
\hline Madeiras & $8 \mathrm{Kg}$ \\
\hline \multicolumn{2}{|c|}{ Step Chair } \\
\hline Estrutura metálica & $8 \mathrm{Kg}$ \\
\hline Madeiras & $4 \mathrm{Kg}$ \\
\hline Caixa molas & $4 \mathrm{Kg}$ \\
\hline
\end{tabular}

Tabela 1: Peso de componentes.

O estudo do processo de montagem dos equipamentos levou a identificação dos deslocamentos, estes foram codificados e foi simulada a distância correspondente a cada um deles (Tabela 2). Os equipamentos não são montados em conjunto pelas montadoras, cada uma é responsável pela montagem inteira do equipamento, exceto para algumas atividades de deslocamento e movimentação de componentes maiores. $\mathrm{O}$ Apêndice A mostra a relação das atividades de montagem dos equipamentos, os deslocamentos envolvidos e o tempo dessas atividades.

\begin{tabular}{|c|c|c|c|}
\hline Origem & Destino & Cod. & Dist.(m) \\
\hline \multirow{19}{*}{ Posto } & Estoque Componentes & 1.1 & 5,81 \\
\hline & Estoque Metais & 1.2 & 4,98 \\
\hline & $\begin{array}{l}\text { Estoque Estofados } \\
\text { (Embalagens atrás do posto) }\end{array}$ & 1.3 & 3,61 \\
\hline & Estoque Madeira CD e RF & 1.4 & 8,31 \\
\hline & Estoque de embalagens & 1.5 & 9,95 \\
\hline & Estoque do Almoxarifado & 1.6 & 8,57 \\
\hline & Estoque Carrinho RF & 1.7 & 5,18 \\
\hline & Embalagem Bancada & 1.8 & 3,61 \\
\hline & Gabarito CD & 1.10 & 5,1 \\
\hline & Gabarito RF & 1.11 & 1,7 \\
\hline & Lixo & 1.12 & 7,75 \\
\hline & Fora & 1.13 & 12,69 \\
\hline & Rolo de Plástico Bolha & 1.14 & 5,2 \\
\hline & Papelão & 1.15 & 8,4 \\
\hline & Faca & 1.16 & 4,13 \\
\hline & Cavalete & 1.17 & 7,81 \\
\hline & Rolinho Plástico Bolha & 1.19 & 5,36 \\
\hline & Rebitadeira & 1.20 & 4,85 \\
\hline & Caixa de Ferramenta & 1.21 & 1,35 \\
\hline \multirow{6}{*}{$\begin{array}{l}\text { Embalagem } \\
\text { Bancada }\end{array}$} & Rolo de Plástico Bolha & 2.1 & 3,91 \\
\hline & Fita Gomada & 2.2 & 3,56 \\
\hline & Caixa de Ferramenta & 2.3 & 2,65 \\
\hline & Estoque de embalagens & 2.4 & 6,76 \\
\hline & Estoque Madeira CD e RF & 2.5 & 4,16 \\
\hline & Faca & 2.6 & 5,33 \\
\hline
\end{tabular}

\begin{tabular}{|c|l|l|l|}
\hline & Gabarito CD & 2.7 & 4,21 \\
\cline { 2 - 4 } & $\begin{array}{l}\text { Estoque Estofados } \\
\text { (Embalagens) }\end{array}$ & 2.8 & 6,4 \\
\cline { 2 - 4 } & Fechar Embalagem & 2.9 & 7,76 \\
\hline $\begin{array}{c}\text { Estoque } \\
\text { Metais }\end{array}$ & Rebitadeira & 3.1 & 6,66 \\
\hline Cavalete & Estoque Madeira CD e RF & 3.2 & 1,88 \\
\hline Cavalete & Estoque Componentes & 3.3 & 4,28 \\
\hline Cavalete & Caixa de Ferramenta & 3.4 & 4,65 \\
\hline $\begin{array}{c}\text { Estoque do } \\
\text { Almoxarifado }\end{array}$ & Rebitadeira & 3.5 & 13,5 \\
\hline Rebitadeira & Caixa de Ferramenta & 3.6 & 3,55 \\
\hline Gabarito CD & Estoque do Almoxarifado & 3.7 & 5,85 \\
\hline
\end{tabular}

Tabela 2: Codificação e distância percorrida dos deslocamentos.

A distância percorrida durante a montagem do Reformer é aproximadamente 767,5m, o tempo estimado de para o processo de montagem é de 78,5 minutos (4711s) sendo que as atividades de montagem levam 50 minutos (2977s), portanto $36,34 \%$ do tempo do processo é deslocamento. A Figura 3 mostra o deslocamento segundo o processo descrito do Reformer; o deslocamento dos demais equipamentos é apresentado no Apêndice A.

Para a montagem do Ladder Barrel a montadora desloca-se aproximadamente $255 \mathrm{~m}$, o tempo do processo de montagem é aproximadamente 21 minutos (1261s) sendo que 14 minutos (817s) são usados em atividades de montagem, se estima que o deslocamento consuma $35,37 \%$ do tempo de montagem. A distância aproximada percorrida no processo de montagem da Step Chair é de 193m, o processo demora aproximadamente 29 minutos (1690s), sendo que desses 22 minutos (1358s) são com operações de montagem, portanto $19,6 \%$ do processo são deslocamentos. Na montagem do Cadilac as montadoras tem um deslocamento médio de $565 \mathrm{~m}$, e levam aproximadamente 52 minutos (3119s), deste tempo apenas 26 minutos (1559s) são de montagem do equipamento. $\mathrm{O}$ tempo de deslocamento consome aproximadamente $50 \%$ do tempo da montagem do equipamento. 


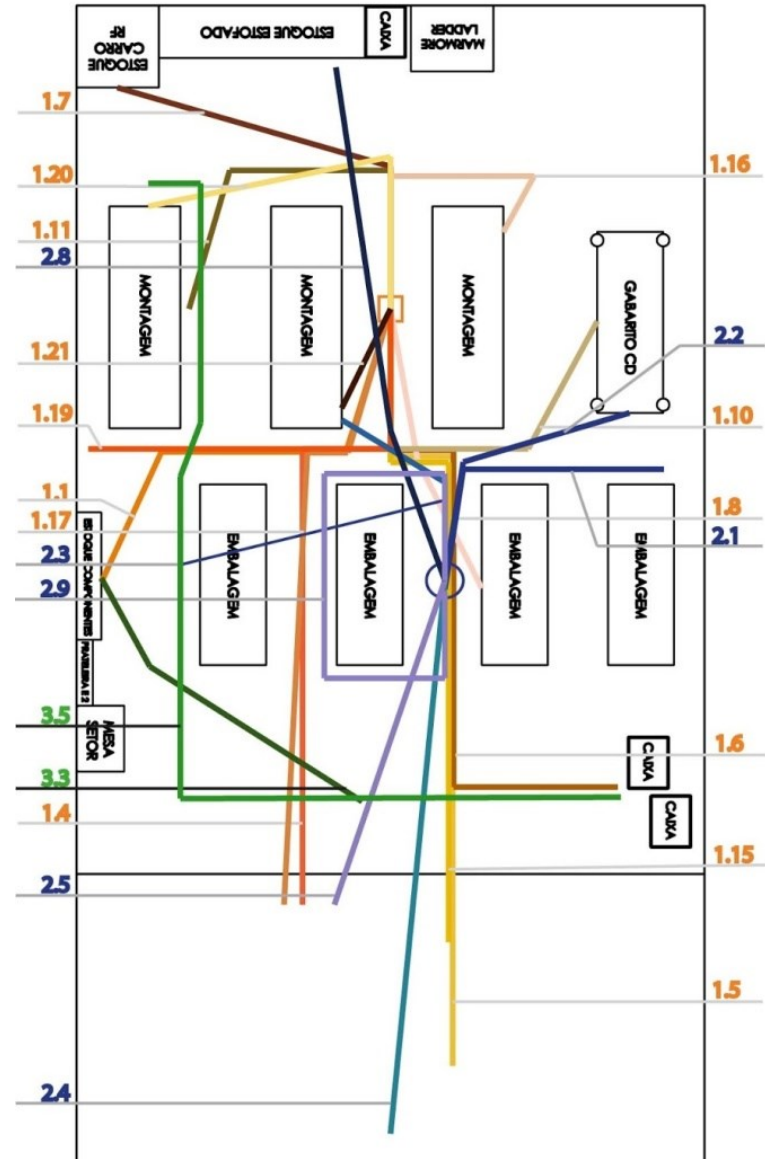

Figura 3: Deslocamento montagem Reformer - estado atual.

Considerando os produtos aqui apresentados, a porcentagem média de desperdício com deslocamentos ao montar o equipamento é $35,3 \%$, a Tabela 3 mostra os dados das montagens dos equipamentos.

\begin{tabular}{|l|c|c|c|}
\hline Equipamento & Tempo total & Deslocamento & $\begin{array}{c}\% \text { de } \\
\text { Deslocamento }\end{array}$ \\
\hline Cadilac & $52 \mathrm{~min}$ & $564,54 \mathrm{~m}$ & $50 \%$ \\
\hline Reformer & $78,5 \mathrm{~min}$ & $767,5 \mathrm{~m}$ & $36,34 \%$ \\
\hline Ladder $B$. & $21 \mathrm{~min}$ & $255,39 \mathrm{~m}$ & $35,37 \%$ \\
\hline Step Chair & $29 \mathrm{~min}$ & $192,89 \mathrm{~m}$ & $19,6 \%$ \\
\hline
\end{tabular}

Tabela 3: Desperdícios resumidos.

Os deslocamentos são realizados carregando pesos entre $2 \mathrm{~kg}$ e $10 \mathrm{~kg}$, como indicado na Tabela 1 , isto faz com que o trabalho se torne mais cansativo, podendo ser relacionado com as dores relatadas pelas montadoras nos quadris, joelhos, tornozelos e pés. Essas dores também podem estar relacionadas com a inexistência de uma cadeira para descanso no setor, como consta na norma NR17, levando a ter sobrecargas nos membros inferiores.
Necessita ser repensado o processo de trabalho das montadoras, para evitar os deslocamentos excessivos apresentados. Ao montar um equipamento a montadora é capaz de se deslocar quase 800 metros dentro do próprio setor.

Ao serem analisados os dados é possível perceber que entre as montadoras existe uma discrepância sobre seu processo de montagem, algumas vezes se percebe o deslocamento pelo esquecimento de componentes ou vários deslocamentos por não conseguir carrega-los em apenas uma viagem.

\section{Proposta de melhoria de Layout e processo de montagem}

Tendo em vista as falhas do layout e processo de montagem identificados por meio da observação das montadoras em sua atividade de trabalho, foi desenvolvida uma nova proposta de layout e processo para o setor que visa maximizar a produtividade e minimizar os desconfortos na execução da atividade de montagem.

Dentre as mudanças necessárias percebeu-se a necessidade de remodelar e reorganizar os estoques e bancadas; definição e fixação de pontos de armazenamento de materiais e equipamentos de modo que estejam próximos ao local de uso, implementação de informações de segurança, entre outros.

A definição do novo layout teve como base a otimização do processo de montagem. Assim buscou-se que para montar um equipamento as montadoras passassem nos estoques apenas uma vez, e não diversas vezes como vem acontecendo no estado atual, para isso foi desenvolvido a ideia do carrinho de transporte (Figura 4). O carrinho poderá acomodar a caixa de peças do almoxarifado, e diversos componentes necessários na montagem. Porém isso só será possível com a mudança de layout mudando os fluxos do setor. O Apêndice B traz uma relação da sequência de atividades propostas para essa proposta. 


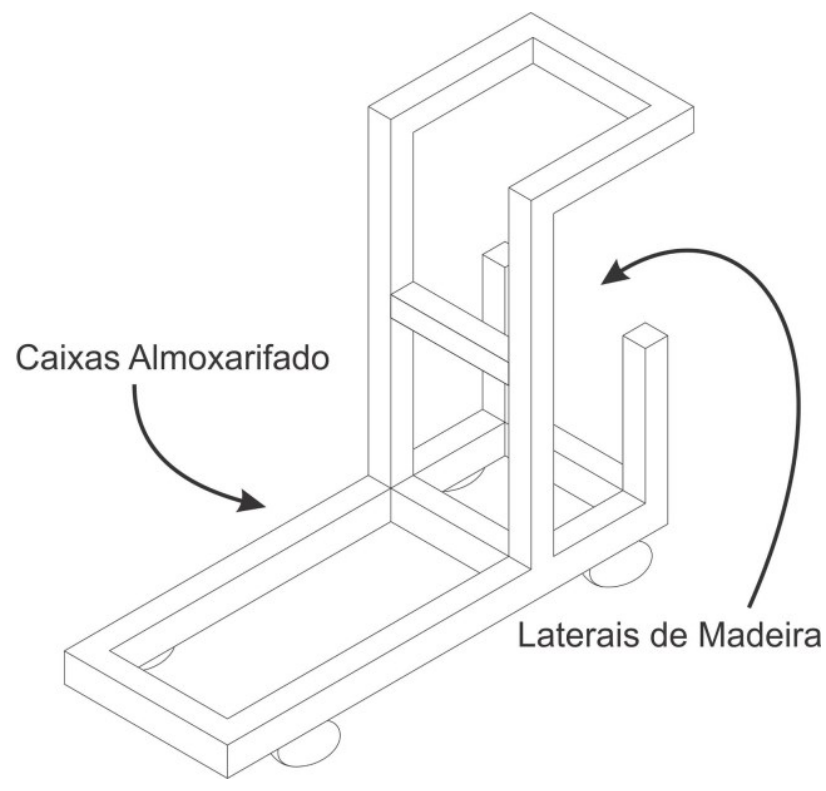

Figura 4: Carrinho de apoio para montagem.

No Layout proposto considera que a montadora com o carrinho, irá até o estoque de almoxarifado pegar a caixa de peças, passar pelo estoque de estofados e passar no estoque de componentes para então ir até sua bancada de montagem. O layout também prevê uma área entre bancada de montagem e as bancadas de embalagem para ser feita a embalagem da Step Chair e Ladder Barrel (feitas no chão), de forma que não obstrua o fluxo de passagem. Do mesmo modo continue a existir um espaço entre a bancada de embalagem e os estoques de madeira do Cadilac e Reformer para a montagem dos cavaletes utilizados de apoio para montagem das peças maiores destes equipamentos (sendo que esse talvez possa ser montado nas bancadas de embalagens). A Figura 5 mostra a o layout aqui proposto.

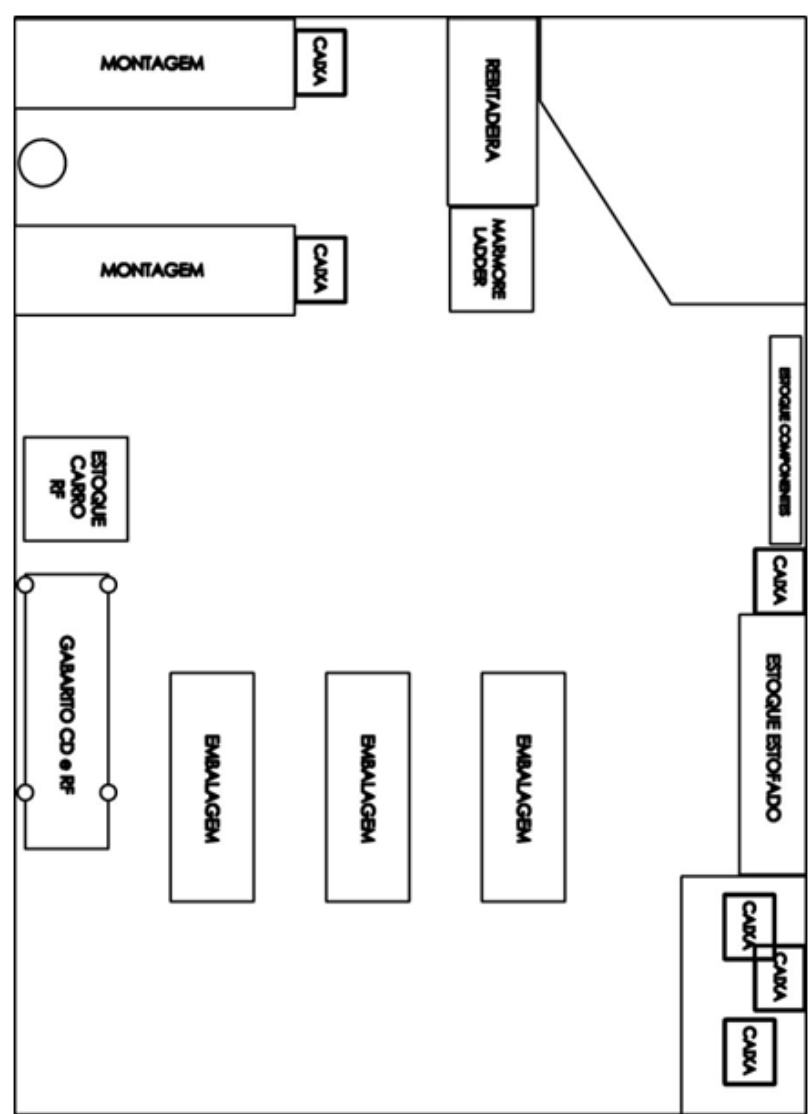

Figura 5: Proposta de layout.

\section{Resultados}

Com a definição do novo layout e estudando os fluxos necessários para o procedimento de montagem, novos deslocamentos seriam realizados para efetuar a montagem, esses deslocamentos são apresentados na Tabela 4, também são apresentadas estimativas das distancias que seriam percorridas com considerando os ajustes recomendados para o layout e a implementação de um carrinho de apoio para as atividades de montagem (Figura 5). Este Carrinho seria utilizado para recolher o material necessário para a montagem dos produtos, como um supermercado, e assim passar pelos estoques apenas uma vez.

\begin{tabular}{|c|c|c|c|}
\hline Origem & Destino & Cod. & Dist. (m) \\
\hline \multirow{4}{*}{ Posto } & Estoque consumíveis & 1.1 & 7,525 \\
\cline { 2 - 4 } & Bancada Rebite & 1.2 & 2,829 \\
\cline { 2 - 4 } & Estoque metais & 1.3 & 6,855 \\
\cline { 2 - 4 } & Gabarito & 1.4 & 6,984 \\
\cline { 2 - 4 } & Bancada embalagem & 1.5 & 6,248 \\
\cline { 2 - 4 } & Estoque almoxarifado & 1.6 & 9,203 \\
\cline { 2 - 4 } & Estoque carrinho & 1.7 & 5,194 \\
\cline { 2 - 4 } & Estoque madeiras CD/RF & 1.8 & 10,869 \\
\hline
\end{tabular}


Ergodesign \& HCI

número especial, volume 5 , ano 5 (2017) ISNN 2317-8876, Rio de Janeiro - Brasil
PUC-Rio Pontifícia Universidade Católica do Rio de Janeiro Departamento de Artes \& Design | PPGDesign

LEUI | Laboratório de Ergodesign e Usabilidade de Interfaces

\begin{tabular}{|c|c|c|c|}
\hline \multirow{4}{*}{ Est. Cons. } & Cavaletes & 1.9 & 11,553 \\
\cline { 2 - 4 } & base mármore & 1.10 & 2,941 \\
\cline { 2 - 4 } & Bancada embalagem & 2.1 & 3,866 \\
\hline Est. Almox. & Estoque Estofados & 2.2 & 3,957 \\
\hline \multirow{2}{*}{ Est. Metais } & Bancada rebite & 2.4 & 2,025 \\
\cline { 2 - 4 } & Gabarito & 2.5 & 8,057 \\
\hline Est. Car & Estoque madeiras CD/RF & 2.6 & 6,698 \\
\hline & Estoque madeiras CD/RF & 3.1 & 3,089 \\
\cline { 2 - 4 } & Estoque de embalagens & 3.2 & 5,8 \\
\cline { 2 - 4 } B. & Cavaletes & 3.3 & 2,78 \\
\cline { 2 - 4 } Embalag. & Estoque metais & 3.4 & 6,387 \\
\cline { 2 - 4 } & Gabarito & 3.5 & 0,942 \\
\cline { 2 - 4 } & Base mármore & 3.6 & 3,688 \\
\hline \multirow{3}{*}{ Cavaletes } & Estoque madeiras CD/RF & 4.1 & 2,564 \\
\cline { 2 - 4 } & Estoque de embalagens & 4.2 & 4,749 \\
\cline { 2 - 4 } & Estoque carrinho & 4.3 & 8,273 \\
\hline
\end{tabular}

Tabela 4 Deslocamentos para layout sugerido.

Na montagem do Reformer, o processo sugerido apresenta um deslocamento calculado de $121,1 \mathrm{~m}$, tendo uma redução de $646,33 \mathrm{~m}$ comparada a estimativa do processo atual. A Figura 6 mostra o deslocamento previsto para esse novo processo.

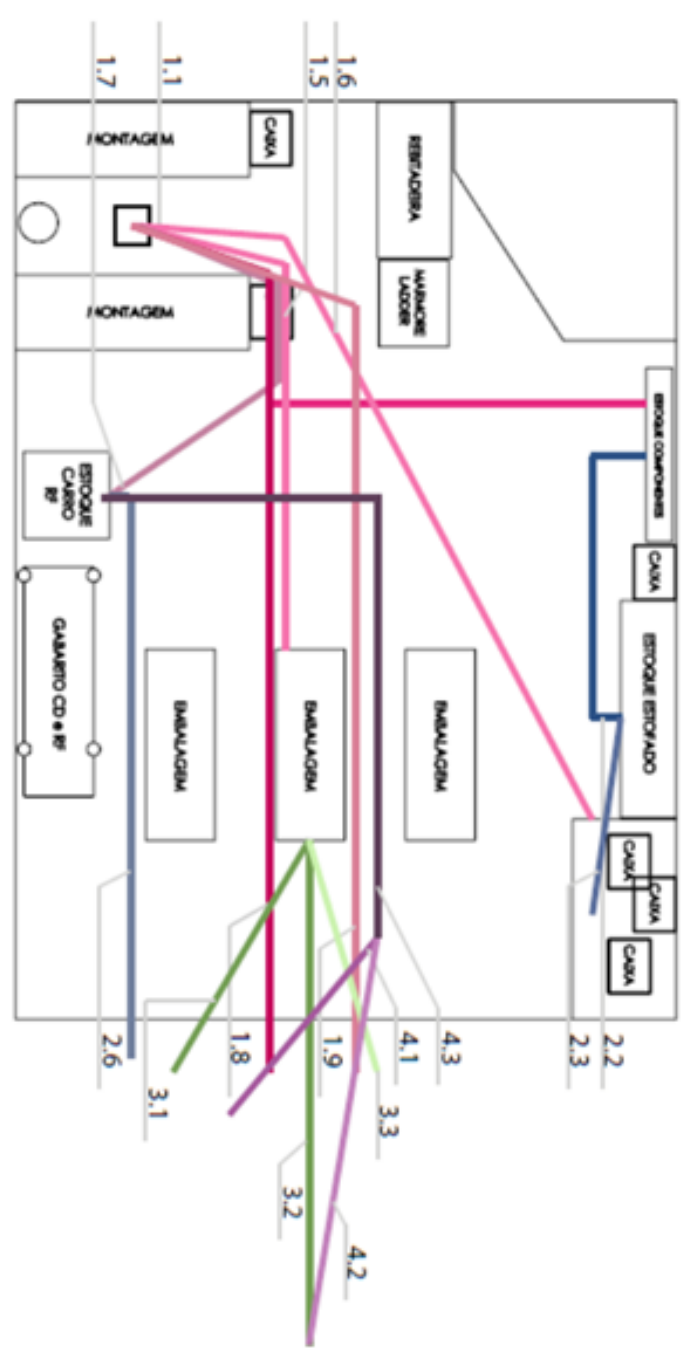

Figura 6: Deslocamentos processo sugerido - Reformer

Já nas montagens dos outros equipamentos como Ladder Barrel, o processo sugerido apresenta resultados simulados de deslocamento calculado de $66,3 \mathrm{~m}$, tendo uma redução de $189,1 \mathrm{~m}$ comparada a estimativa do processo atual. Na montagem da Step Chair, o processo sugerido apresenta um deslocamento calculado de 53,44m, tendo uma redução de 139,45m comparada a estimativa do processo atual. Por fim a montagem do Cadillac, o processo sugerido apresenta um deslocamento calculado de $166,33 \mathrm{~m}$, tendo uma redução de $398,21 \mathrm{~m}$ comparada a estimativa do processo atual.

Considerando os produtos aqui apresentados, a porcentagem média da redução com deslocamentos ao montar o equipamento no layout simulado é $75,25 \%$. A Tabela 5 apresenta a redução de cada equipamento. 


\begin{tabular}{|l|c|c|c|c|}
\hline & & $(\mathbf{m})$ & $(\mathbf{m})$ & Redução \\
\hline Cadilac & 564,54 & 166,33 & 398,21 & $71 \%$ \\
\hline Reformer & 767,5 & 121,17 & 646,33 & $84 \%$ \\
\hline Ladder B. & 255,39 & 66,32 & 189,08 & $74 \%$ \\
\hline Step Chair & 192,89 & 53,44 & 139,45 & $72 \%$ \\
\hline
\end{tabular}

Tabela 5 Melhorias estimadas.

\section{Discussão}

A ergonomia deve ser aplicada desde as etapas iniciais do projeto de uma máquina, sistema, ambiente ou local de trabalho. Estas devem sempre incluir o ser humano como um de seus componentes. Assim, as características ou restrições das partes mecânicas, sistêmicas ou ambientais, para se ajustarem mutuamente umas às outras. A ergonomia contribui para melhorar a eficiência, a confiabilidade e a qualidade das operações industriais. Isso pode ser feito basicamente por três vias: aperfeiçoamento do sistema homem-máquina-ambiente, organização do trabalho e melhoria das condições de trabalho (IIDA, 2005).

O sistema homem-máquina, ambiente, organização do trabalho e a melhoria das condições do trabalho estão relacionadas às mudanças sugeridas no setor de montagem da empresa analisada, pois as alterações propostas no layout e dos fluxos no processo de montagem podem levar a melhor organização do trabalho e das condições de trabalho das funcionárias. A alteração no layout tem influências em questões produtivas e organizacionais de um lado, e de outro, questões pessoais e motivacionais dos funcionários.

Dentre os resultados do trabalho foi percebido o impacto que o layout tem sobre o processo de trabalho, logo na produtividade do trabalhador. Lembrando que Guérin et al. (2001) diz que atividade de um operador é influenciada por diversos fatores, alguns externos ao operador e outros internos, dentre os fatores externos estão os objetivos determinados pela empresa, como a meta de produção e os meios postos a sua disposição como mobiliários dispostos em um layout. Mudanças de layout e postos de trabalho resultaram em melhorias na produtividade e redução considerável dos níveis de fadiga e número de lesões no estudo realizado por Battini et al. (2011), e Sotsek e Bonduelle (2016) observaram a redução do tempo de montagem (reduções em torno de $29 \%$ e $33 \%)$.
Ainda relacionado aos aspectos produtivos, Fiedler et al. (2009) sugere que para um bom fluxo de produção, os equipamentos devem estar dispostos em linha reta, evitando-se ao máximo mudanças de fluxo em ângulos, além de evitar o retrocesso das peças. No estado atual isso não acontece, como mostra a Figura 1 muitos dos deslocamentos têm uma mudança de trajeto devido à disposição do mobiliário, o que foi reduzido na proposta de layout (Figura 2 e 3 ).

O layout possui valor quando é instalado para benefício dos usuários, que podem ser os operários ou os proprietários da empresa (MUTHER, 1978). Fiedler et al. (2009) diz que a locação dos equipamentos quanto a sequência lógica de produção, distâncias mínimas necessárias entre máquinas, áreas destinadas a resíduos e locais necessários para pausas, entre outros fatores, favorece o ambiente de trabalho, trazendo motivação e qualidade de vida ao trabalhador, e pode gerar, assim, maior produtividade. Considerando nas simulações houve em média uma redução $75 \%$ dos deslocamentos no processo de montagem, espera-se que a capacidade produtiva no setor aumente e consequentemente o melhor rendimento do trabalho e motivação dos envolvidos.

\section{Conclusão}

O presente artigo tinha como hipótese que os deslocamentos efetuados pelas colaboradoras do setor de montagem eram demasiados gerando sobrecarga nos membros inferiores e sensação de improdutividade. Conclui-se que a essa afirmação pode ser considerada parcialmente correta. Os deslocamentos são demasiados, pois sua média de deslocamento é de $445 \mathrm{~m}$ podendo chegar até $767,5 \mathrm{~m}$ entre os quatro equipamentos analisados, podendo consumir em média $35 \%$ do tempo de montagem. A sobrecarga nos membros inferiores pode estar atrelada também a outros fatores, como por exemplo, a realização de todas as atividades em pé, falta de cadeiras de apoio no setor.

Dos objetivos do artigo, desenvolver a análise de deslocamentos para o setor de montagem, como resultado a simulação dos deslocamentos em um novo layout e com novos fluxos de trabalho juntamente com a adoção de um carrinho de apoio demonstrou uma melhoria média de $75 \%$ dos deslocamentos, tendo uma redução média de $343 \mathrm{~m}$. No caso do Reformer chegou apresentar uma 
redução de 646m representando 84\%.

Para trabalhos futuros seria dado pela implementação do novo layout no setor de montagem da empresa, e verificar os resultados simulados; assim como estender os estudos para demais setores da empresa.

\section{Referências Bibliográficas}

BARNES, R. M. Estudo de movimentos e de tempos: projeto e medida do trabalho. 6 . ed. São Paulo: Edgar Blücher, 1977.

BATTINI, D. et al. New methodological framework to improve productivity and ergonomics in assembly system design. International Journal of Industrial Ergonomics, v. 41, n. 1, p. 30-42, 2011.

DAS, B.; SENGUPTA, A. K. Industrial workstation design: A systematic ergonomics approach. Applied Ergonomics, v. 27, n. 3, p. 157-163, 1996.

FIEDLER, N. C. et al. Otimização do Layout de marcenarias no sul do Espírito Santo baseado em parâmetros ergonômicos e de produtividade. Revista Árvore, v. 33, n. 1, p. 161-170, 2009.

GUÉRIN, F. et al. Compreender o trabalho para transformá-lo: a prática da ergonomia. São Paulo: Edgard Blucher, 2001.

IIDA, I. Ergonomia: projeto e produção. 2a ed. rev ed. São Paulo: Blucher, 2005.

RESNICK, M. L.; ZANOTTI, A. Using Ergonomics To Target Productivity Improvements. Computers ind. Engng, v. 33, n. 12, p. 185-188, 1997.

ROSA, G. et al. Reorganizing the layout as a production optimization strategy. Revista Gestão da Produção, Operações e Sistemas, v. 9, n. 2, p. 139-154, 2014.

SHINDE, G. V.; JADHAV, V. S. 'Ergonomic analysis of an assembly workstation to identify time consuming and fatigue causing factors using application of motion study'. International Journal of Engineering and Technology, v. 4, n. 4, p. 220 227, 2012.

SOTSEK, N. C.; BONDUELLE, G. M. Melhorias em uma empresa de embalagens de madeira através da utilização da cronoanálise e rearranjo de layout. Floresta, v. 46, n. 4, p. 519-530, 2016.

\section{Agradecimentos}

Os agradecimentos às instituições de apoio e fomento à pesquisa: Universidade Federal de Santa Catarina(UFSC), Universidade do Estado de Santa Catarina (UDESC), Coordenação de Aperfeiçoamento de Pessoal de Nível Superior (CAPES) e ao Conselho Nacional de Desenvolvimento Cientifico e Tecnológico (CNPq). 


\section{Apêndice A}

Neste tópico são apresentadas as atividades realizadas na montagem dos equipamentos, o deslocamento envolvido e o tempo de execução. Os deslocamentos envolvidos no processo de montagem também são mostrados graficamente.

\section{Processo Montagem Cadilac}

\begin{tabular}{|c|c|c|}
\hline Ações & Deslocamento & Tempo (s) \\
\hline Pega os cavaletes e os posiciona; & 1.17 & 25 \\
\hline \multirow[t]{2}{*}{ Solicita ajuda para levar a base e estofado para os cavaletes(duas viagens); } & 3.2 & 3 \\
\hline & 3.2 & 3 \\
\hline \multirow[t]{2}{*}{ Pega parafusos (estoque de consumíveis); } & 3.3 & 5 \\
\hline & 3.3 & 5 \\
\hline \multirow[t]{2}{*}{ Pega a parafusadeira e monta a base; } & 3.4 & 9 \\
\hline & 3.4 & 9 \\
\hline Monta a base do cadilac no estofado & & 116 \\
\hline \multirow[t]{2}{*}{ Pega fita adesiva e caixa - monta a caixa; } & 3.4 & 9 \\
\hline & 3.4 & 9 \\
\hline Leva a caixa até a bancada de embalagens; & 2.4 & 40 \\
\hline \multirow[t]{2}{*}{ Pega a fita gomada e cola os cantos; } & \multirow[t]{2}{*}{2.2} & 30 \\
\hline & & 30 \\
\hline \multirow[t]{2}{*}{ Pega plástico bolha e forra a caixa; } & 2.1 & 10 \\
\hline & 2.1 & 10 \\
\hline \multirow[t]{2}{*}{ Pede ajuda e leva base para a caixa; } & 2.5 & 15 \\
\hline & 2.5 & 15 \\
\hline \multirow{4}{*}{$\begin{array}{l}\text { Vai até o estoque (caixas vindas do almoxarifado) e pega as peças a serem rebitada se leva até a } \\
\text { bancada de montagem/rebite ( } 2 \text { viagens); }\end{array}$} & 1.6 & 12 \\
\hline & 3.5 & 20 \\
\hline & 3.5 & 20 \\
\hline & 3.5 & 20 \\
\hline \multirow[t]{2}{*}{ Rebita ou martela (pega o martelo) as peças; } & 3.6 & 5 \\
\hline & 3.6 & 5 \\
\hline \multicolumn{3}{|l|}{ Martela e rebita as peças do Cadilac } \\
\hline duas travessas pretas & & 50 \\
\hline Duas travessas inox & & 40 \\
\hline \multirow[t]{2}{*}{ Leva as peças rebitadas para a bancada; } & 1.20 & 10 \\
\hline & 1.20 & 10 \\
\hline \multirow[t]{4}{*}{ Pega cola e buchas (estoque de consumíveis) e cola; } & 1.1 & 10 \\
\hline & 1.1 & 10 \\
\hline & 1.1 & 10 \\
\hline & 1.1 & 10 \\
\hline Coloca os olhais 35 cada par de olhal ( travessa 1 preta) & & 35 \\
\hline Cola as buchas na travessa, limpa as buchas & & 65 \\
\hline \multicolumn{2}{|l|}{\begin{tabular}{|l} 
Coloca os olhais 35 cada par de olhal (travessa 2 preta) \\
\end{tabular}} & 70 \\
\hline Cola as buchas na travessa, limpa as buchas & & 65 \\
\hline \multicolumn{3}{|l|}{\begin{tabular}{|c|c|c|} 
Coloca os olhais 35 cada par de olhal ( travessas inox ) \\
\end{tabular}} \\
\hline \multicolumn{3}{|l|}{ Coloca o Y nas travessas de inox } \\
\hline \multirow[t]{2}{*}{ Pega parafusadeira e macho - passa o macho; } & 1.21 & 6 \\
\hline & 1.21 & 6 \\
\hline \multirow[t]{2}{*}{ Volta ao estoque (caixas) e pega os ganchos - monta os ganchos; } & 1.1 & 10 \\
\hline & 1.1 & 10 \\
\hline Volta ao estoque (caixas) e pega as peças de inox e coloca no gabarito ( 2 viagens); & 1.6 & 10 \\
\hline & 3.7 & 10 \\
\hline & 3.7 & 10 \\
\hline & 3.7 & 10 \\
\hline & 3.7 & 10 \\
\hline Volta ao estoque do almoxarifado e pega dois inox de cima e pega os conectores "y". & 1.10 & 10 \\
\hline & 1.6 & 12 \\
\hline & 1.6 & 12 \\
\hline & 1.6 & 12 \\
\hline & 1.6 & 12 \\
\hline Vai até o estoque de componentes e pega os parafuros do Y & 1.1 & 10 \\
\hline & 1.1 & 10 \\
\hline Monta todo o quadro de inox da parte de cima e monta & & 85 \\
\hline Pede ajuda para colocar a base superior no gabarito; & 1.10 & 10 \\
\hline & 1.10 & 10 \\
\hline Passa o o macho nos y & & 50 \\
\hline
\end{tabular}




\begin{tabular}{|c|c|c|}
\hline \multirow[t]{2}{*}{ Ela troca item na parafusadeira } & 1.21 & 6 \\
\hline & 1.21 & 6 \\
\hline E coloca os parafusos & & 35 \\
\hline \multirow{2}{*}{ Vai até os componentes e pega as buchinhas do inox cadillac } & 1.1 & 10 \\
\hline & 1.1 & 10 \\
\hline Martela as buchas (15 segundos) & & 90 \\
\hline Lubrifica, testa e coloca silicone & & 360 \\
\hline \multirow[t]{2}{*}{ Pega o silicone e o lubrificante } & 1.1 & 10 \\
\hline & 1.1 & 10 \\
\hline \multirow[t]{2}{*}{ Pede ajuda para colocar parte superior na bancada. } & 1.10 & 10 \\
\hline & 1.10 & \multirow{7}{*}{560} \\
\hline \multirow[t]{2}{*}{ Pega rolinhos de plástico bolha e volta para bancada; } & 1.19 & \\
\hline & 1.19 & \\
\hline \multirow[t]{2}{*}{ Embala as travessas e mancais com plástico bolha; } & 1.21 & \\
\hline & 1.21 & \\
\hline \multirow[t]{2}{*}{ Pega papel de divisória/suporte - dobra e coloca na embalagem; } & 1.5 & \\
\hline & 2.4 & \\
\hline \multirow{4}{*}{ Leva as peças para a embalagem limpado de novo as peças de inox; } & 2.7 & 5 \\
\hline & 2.7 & 5 \\
\hline & 2.7 & 5 \\
\hline & 2.7 & 5 \\
\hline \multirow{2}{*}{ Pega a alça trapezio embalada e coloca na embalagem } & 2.7 & 5 \\
\hline & 2.7 & 5 \\
\hline \multirow[t]{4}{*}{ Pega os pés e coloca na embalagem (2 viagens); } & 2.4 & 12 \\
\hline & 2.4 & 12 \\
\hline & 2.4 & 12 \\
\hline & 2.4 & 12 \\
\hline \multirow[t]{2}{*}{ Vai em baixo da bancada e pega caixa, embala (2 viagens); } & 1.8 & 10 \\
\hline & 1.8 & 10 \\
\hline Agachar e Pegar a embalagem & & 20 \\
\hline \multirow[t]{2}{*}{ Pega trapézio no estoque de estofados, coloca na embalagem principal; } & 2.8 & 8 \\
\hline & 2.8 & 8 \\
\hline Cobre com plástico bolha; e ajeita a caixa & & 60 \\
\hline Leva a caixa até a bancada de embalagens & 2.4 & 12 \\
\hline Monta a caixa com fita adesiva & & 20 \\
\hline \multirow[t]{2}{*}{ Pega a fita gomada e cola os cantos; } & 2.2 & 30 \\
\hline & 2.2 & 30 \\
\hline Fecha a caixa - pega a fita adesiva na caixa de ferramenas e a pega a fita gomada lacra a caixa; & 2.3 & 6 \\
\hline & 2.3 & 6 \\
\hline & 2.9 & 120 \\
\hline Pega caneta na caixa de ferramentas e anota pedido na caixa, devolve a caneta para a caixa de & 2.3 & 6 \\
\hline ferramentas. & 2.3 & 6 \\
\hline Montagem Mancais & & \\
\hline Pega os mancais no estoque de almoxarifado & 1.6 & 12 \\
\hline & 1.6 & 12 \\
\hline Pega os componentes no estoque de componentes & 1.1 & 10 \\
\hline & 1.1 & 10 \\
\hline Passa o Macho e coloca as buchas & 1.21 & 20 \\
\hline & 1.21 & 20 \\
\hline Coloca a bucha 2 & & 10 \\
\hline Coloca a bucha 1 & & 10 \\
\hline Coloca a bucha 3 & & 10 \\
\hline Coloca a bucha 4 & & 10 \\
\hline Embala com rolinhos e coloca na caixa & 1.19 & 15 \\
\hline & 1.19 & 15 \\
\hline Embala com rolinhos e coloca na caixa & 1.19 & 15 \\
\hline & 1.19 & 15 \\
\hline Busca a embalagem das caixas & 1.5 & 15 \\
\hline & 1.5 & 15 \\
\hline Monta as caixas e passa fita & 1.21 & 6 \\
\hline & 1.21 & 6 \\
\hline Pega os acessorios no estoque do almoxarifado & 1.6 & 12 \\
\hline & 1.6 & 12 \\
\hline fecha a caixa & 2.9 & 142 \\
\hline Leva as duas caixas até a embalagem & 1.5 & 15 \\
\hline & 1.5 & 15 \\
\hline Vai até o estoque de componentes e pega o adesivo & 1.1 & 10 \\
\hline
\end{tabular}




\begin{tabular}{|c|c|}
\hline 1.1 & 10 \\
\hline & 15 \\
\hline
\end{tabular}

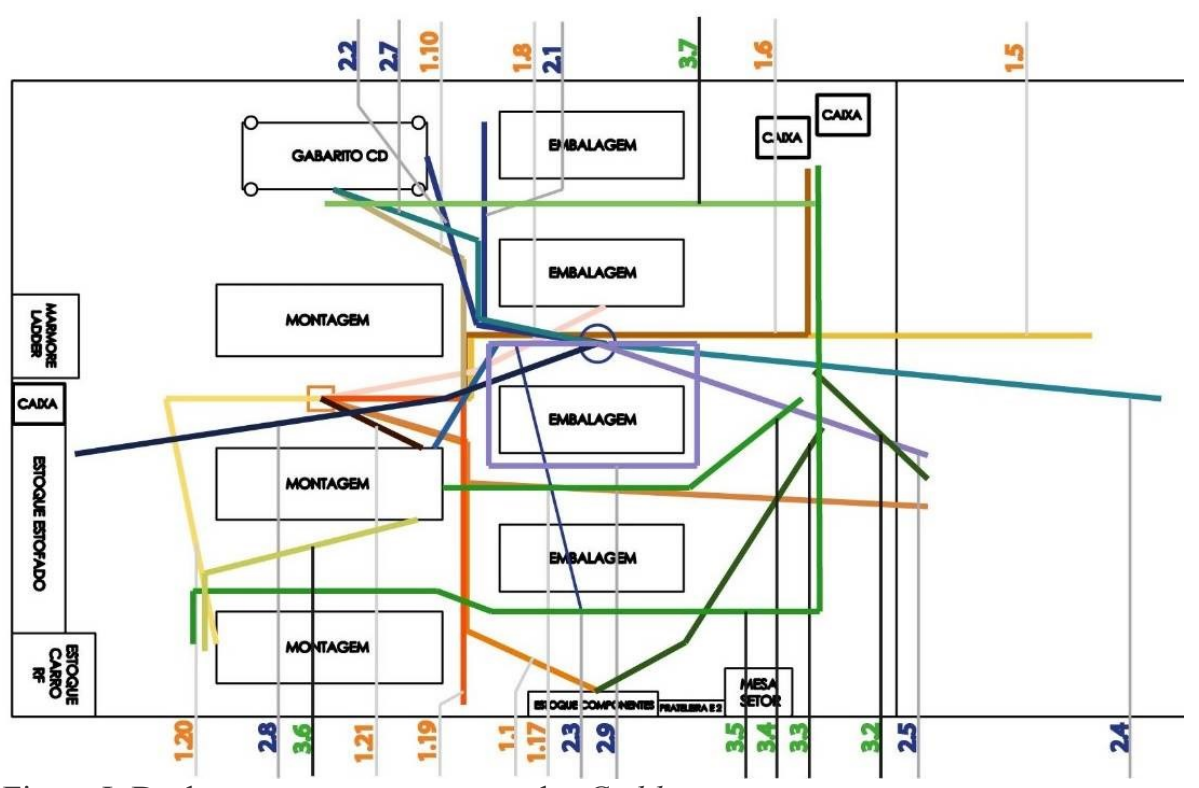

Figura I: Deslocamentos processo atual - Cadilac.

Processo Montagem Reformer

\begin{tabular}{|c|c|c|}
\hline Ações & Deslocamento & Tempo(s) \\
\hline \multicolumn{3}{|l|}{ Montagem Carrinho } \\
\hline \multirow[t]{2}{*}{ Pega no estoque a base de metal e leva para bancada; } & 1.6 & 12 \\
\hline & 1.6 & 12 \\
\hline \multirow[t]{2}{*}{ Pega as molas no estoque e leva para a bancada - monta as molas; } & 1.6 & 12 \\
\hline & 1.6 & 12 \\
\hline Monta as molas na base de metal do carrinho & & 150 \\
\hline \multirow{2}{*}{ Pega as rodas e rolamentos no estoque e monta as rodas - leva pra a bancada; } & 1.1 & 10 \\
\hline & 1.1 & 10 \\
\hline Monta as rodas no carrinho; & & 240 \\
\hline \multirow[t]{4}{*}{ Pega no estoque o resto do material necessário (2 viagens); } & 1.1 & 10 \\
\hline & 1.1 & 10 \\
\hline & 1.1 & 10 \\
\hline & 1.1 & 10 \\
\hline \multirow[t]{2}{*}{ Pega o estofado no estoque de estofados e monta no carrinho; } & 1.3 & 5 \\
\hline & 1.3 & 5 \\
\hline Monta o Resto do carrinho & & 350 \\
\hline \multirow[t]{2}{*}{ Pega as ombreiras de madeira no estoque de almoxarifado e faz a montagem } & 1.6 & 12 \\
\hline & 1.6 & 12 \\
\hline Faz a montagem das ombreiras madeira no carinho com o estofado & & 180 \\
\hline \multirow[t]{2}{*}{ Guarda o carrinho no estoque ao lado dos estofados. (pede ajuda) } & 1.7 & 9 \\
\hline & 1.7 & 9 \\
\hline \multicolumn{3}{|l|}{ Montagem Alça } \\
\hline \multirow[t]{2}{*}{ Vai no estoque de almoxarifado pega as peças; } & 1.6 & 12 \\
\hline & 1.6 & 12 \\
\hline \multirow[t]{2}{*}{ Vai no estoque de consumíveis e pega parafusos; } & 1.1 & 10 \\
\hline & 1.1 & 10 \\
\hline \multirow[t]{2}{*}{ Pega a faca e tira a rebarba de borracha; } & 1.16 & 5 \\
\hline & 1.16 & 5 \\
\hline \multirow[t]{2}{*}{ Vai para bancada e pega parafusadeira e monta; } & 1.21 & 6 \\
\hline & 1.21 & 6 \\
\hline \multicolumn{3}{|l|}{ Monta a Alça } \\
\hline \multirow[t]{2}{*}{ Pega os rolinhos de plástico bolha e embala; } & 1.19 & 10 \\
\hline & 1.19 & 10 \\
\hline Embala a alça pronta no rolinho de plastico bolha & & 70 \\
\hline \multirow[t]{2}{*}{ Guarda atrás do gabarito $\mathrm{CD}$} & 1.10 & 10 \\
\hline & 1.10 & 10 \\
\hline Guarda a Faca & 1.16 & 5 \\
\hline
\end{tabular}




\begin{tabular}{|c|c|c|}
\hline & 1.16 & 5 \\
\hline \multicolumn{3}{|l|}{ Montagem Base de Madeira } \\
\hline \multirow[t]{2}{*}{ Pede ajuda para levar base de madeira na bancada; } & 1.4 & 10 \\
\hline & 1.4 & 10 \\
\hline \multirow[t]{2}{*}{ Vai ao estoque de consumíveis e pega os parafusos; } & 1.1 & 10 \\
\hline & 1.1 & 10 \\
\hline \multirow[t]{2}{*}{ Vai ao estoque e pega as peças; } & 1.6 & 12 \\
\hline & 1.6 & 12 \\
\hline Posiciona as peças e monta; & & 270 \\
\hline \multirow[t]{2}{*}{ Vai ao estoque e pega trilho de alumínio; } & 1.6 & 12 \\
\hline & 1.6 & 12 \\
\hline Posiciona e monta; & & 67 \\
\hline Pede ajuda e vira a base; & & 6 \\
\hline Monta o outro lado; & & 340 \\
\hline \multirow[t]{2}{*}{ Vai ao estoque pega peças e leva para bancada de rebite; } & 1.6 & 12 \\
\hline & 3.5 & 20 \\
\hline volta ao posto & 1.20 & 8 \\
\hline \multirow[t]{4}{*}{ Coloca os ganchos na peça e o embala as pontas com plastico bolha } & 1.1 & 10 \\
\hline & 1.1 & 10 \\
\hline & 1.19 & 10 \\
\hline & 1.19 & 10 \\
\hline Monta os Cavaletes & 1.17 & 25 \\
\hline \multirow[t]{3}{*}{ Pede ajuda - leva a base até os cavaletes; } & 1.17 & 25 \\
\hline & 3.3 & 12 \\
\hline & 3.3 & 12 \\
\hline Faz pequenas montagens no cavalete; & & 60 \\
\hline \multirow[t]{2}{*}{ Pede ajuda e pega o carrinho no estoque de carrinhos (posto) } & 1.17 & 25 \\
\hline & 1.17 & 25 \\
\hline Testa e prende o carrinho com as molas; & & 60 \\
\hline Leva a caixa até a bancada de embalagens; & 2.4 & 40 \\
\hline Leva a caixa até a bancada de embalagens; & 2.4 & 40 \\
\hline \multirow[t]{2}{*}{ Pega a fita gomada e cola os cantos; } & 2.2 & 30 \\
\hline & & 30 \\
\hline \multirow[t]{2}{*}{ Pega plástico bolha e forra a caixa; } & 2.1 & 10 \\
\hline & 2.1 & 10 \\
\hline \multirow{2}{*}{ Pede ajuda e leva base para a caixa; } & 2.5 & 15 \\
\hline & 2.5 & 15 \\
\hline \multicolumn{3}{|l|}{ Prancha de Salto } \\
\hline Pega a parte de metal no estoque de almoxarifado & 1.6 & 12 \\
\hline & 1.6 & 12 \\
\hline Pega os componentes no estoque de componentes & 1.1 & 10 \\
\hline & 1.1 & 10 \\
\hline Pega o estofado no estoque de estofado & 1.3 & 5 \\
\hline & 1.3 & 5 \\
\hline Monta & & 60 \\
\hline testa no gabarito & 1.11 & 6 \\
\hline & 1.11 & 6 \\
\hline pega o martelo de borracha e ajusta & 1.21 & 6 \\
\hline & 1.21 & 6 \\
\hline Pega rolo de plastico bolha e enrola & 1.19 & 10 \\
\hline & 1.19 & 10 \\
\hline Embala a alça com rolinhos de plastico bolha & & 10 \\
\hline Pega papelão e corta com a tesoura da caixa de ferramentas & 1.21 & 6 \\
\hline & 1.21 & 6 \\
\hline Prancha de Extensão+A97 & 1.15 & 8 \\
\hline & 1.15 & 8 \\
\hline Pega fita adesiva e envolve & 1.21 & 6 \\
\hline & 1.21 & 6 \\
\hline Coloca na embalagem pronta & 1.8 & 130 \\
\hline Prancha de Extensão & & \\
\hline Pega a parte de metal no estoque de almoxerifado & 1.6 & 12 \\
\hline & 1.6 & 12 \\
\hline Pega os componentes no estoque de componentes & 1.1 & 10 \\
\hline & 1.1 & 10 \\
\hline Pega o estofado no estoque de estofado & 1.3 & 5 \\
\hline & 1.3 & 5 \\
\hline monta & & 60 \\
\hline testa no gabarito & 1.11 & 6 \\
\hline & 1.11 & 6 \\
\hline
\end{tabular}




\begin{tabular}{|c|c|c|}
\hline \multirow[t]{2}{*}{ pega o martelo de borracha e ajusta } & 1.21 & 6 \\
\hline & 1.21 & 6 \\
\hline Testa no gabarito & & 6 \\
\hline \multirow[t]{2}{*}{ Pega rolo de plastico bolha e enrola } & 1.19 & 10 \\
\hline & 1.19 & 10 \\
\hline Embala A prancha com rolinhos de plastico bolha & & 130 \\
\hline \multirow[t]{2}{*}{ Pega fita adesiva e envolve } & 1.21 & 6 \\
\hline & 1.21 & 6 \\
\hline Coloca na embalagem pronta & 1.8 & 10 \\
\hline \multicolumn{3}{|l|}{ Montagem Ombreiras } \\
\hline \multirow[t]{2}{*}{ Pega as ombreiras no estoque de almoxerifado } & 1.6 & 12 \\
\hline & 1.6 & 12 \\
\hline \multirow[t]{2}{*}{ Pega o estofado das ombreiras no estoque de estofado } & 1.3 & 5 \\
\hline & 1.3 & 5 \\
\hline \multirow[t]{2}{*}{ Pega os componentes no estoque de componentes } & 1.1 & 10 \\
\hline & 1.1 & 10 \\
\hline Monta & & 45 \\
\hline \multirow{2}{*}{ Embala com rolinhos } & 1.19 & 15 \\
\hline & 1.19 & 15 \\
\hline Embalar e Coloca na caixa & & 10 \\
\hline \multicolumn{3}{|l|}{ Montagem Mancais } \\
\hline \multirow[t]{2}{*}{ Pega os mancais s no estoque de almoxarifado } & 1.6 & 12 \\
\hline & 1.6 & 12 \\
\hline \multirow[t]{2}{*}{ Pega os componentes no estoque de componentes } & 1.1 & 10 \\
\hline & 1.1 & 10 \\
\hline \multirow[t]{2}{*}{ Passa o Macho e coloca as buchas } & 1.21 & 6 \\
\hline & 1.21 & 6 \\
\hline Passar o Macho & & 20 \\
\hline \multirow{2}{*}{ Embala com rolinhos e coloca na caixa } & 1.19 & 15 \\
\hline & 1.19 & 15 \\
\hline Embala os 2 mancais L & & 40 \\
\hline Embala 2 mancais simples & & 15 \\
\hline Embala com rolinhos e coloca na caixa & 1.19 & 15 \\
\hline & 1.19 & 15 \\
\hline Reconta as peças do almoxarifado & & 20 \\
\hline Montagem das Caixas & & \\
\hline Busca a embalagem das caixas & 1.5 & 15 \\
\hline & 1.5 & 15 \\
\hline Monta as caixas e passa fita & 1.21 & 6 \\
\hline & 1.21 & 6 \\
\hline Montagem da Caixa com a fita & & 13 \\
\hline Pega os acessórios no estoque do almoxarifado & 1.6 & 12 \\
\hline & 1.6 & 12 \\
\hline Pega do estoque de componente Saquinho & 1.1 & 10 \\
\hline & 1.1 & 10 \\
\hline Pega do estoque de componentes os parafusos & 1.1 & 10 \\
\hline & 1.1 & 10 \\
\hline Pega no estoque de componente os manípulos & 1.1 & 10 \\
\hline & 1.1 & 10 \\
\hline Reconta e Coloca as coisas na caixa & & 77 \\
\hline fecha a caixa & & 13 \\
\hline Leva as duas caixas até a embalagem & 1.5 & 15 \\
\hline & 1.5 & 15 \\
\hline Pega os pés e coloca na embalagem (2 viagens); & 2.4 & 40 \\
\hline & 2.4 & 40 \\
\hline & 2.4 & 40 \\
\hline & 2.4 & 40 \\
\hline Vai em baixo da bancada e pega caixa, embala (2 viagens); & 1.8 & 10 \\
\hline & 1.8 & 10 \\
\hline Cobre com plástico bolha; & & 60 \\
\hline Leva a caixa até a bancada de embalagens; & 2.4 & 40 \\
\hline Pega a fita gomada e cola os cantos; & 2.2 & 10 \\
\hline & 2.2 & 10 \\
\hline Fecha a caixa - pega a fita adesiva na caixa de ferramentas e a pega a fita gomada lacra a caixa; & 2.3 & 10 \\
\hline & 2.3 & 10 \\
\hline & 2.9 & 142 \\
\hline Pega caneta na caixa de ferramentas e anota pedido na caixa, devolve a caneta para a caixa de ferramentas. & 2.3 & 10 \\
\hline & 2.3 & 10 \\
\hline Vai até o estoque de componentes e pega o adesivo & 1.1 & 10 \\
\hline
\end{tabular}




\begin{tabular}{|l|l|l|}
\hline Volta ao posto & 1.1 & 10 \\
\hline Adesiva as duas laterais & & 15 \\
\hline
\end{tabular}

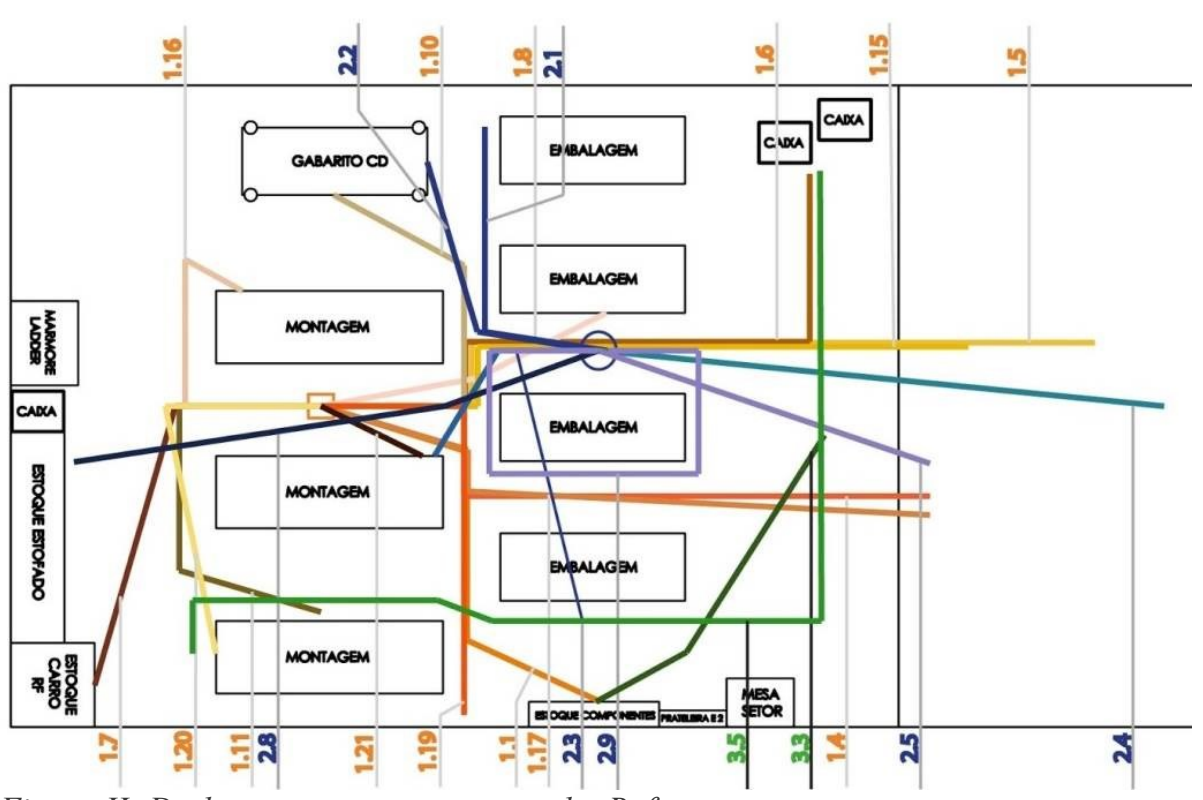

Figura II: Deslocamentos processo atual-Reformer

\section{Processo Montagem Ladder Barrel}

\begin{tabular}{|c|c|c|}
\hline Ações & Deslocamento & Tempo (s) \\
\hline \multirow[t]{2}{*}{ Pega base de metal e leva para rebitar - rebita; } & 1.2 & 8 \\
\hline & 3.1 & 18 \\
\hline Rebita & & 150 \\
\hline Leva para bancada de montagem; & 1.20 & 8 \\
\hline \multirow[t]{2}{*}{ Vai ao estoque de consumíveis e pega os pés - monta; } & 1.1 & 10 \\
\hline & 1.1 & 10 \\
\hline Montagem dos pés & & $20 \mathrm{~s}$ \\
\hline \multirow[t]{4}{*}{ Vai ao estoque e pega os bastoes o ladder; } & 1.6 & 12 \\
\hline & 1.6 & 12 \\
\hline & 1.6 & 12 \\
\hline & 1.6 & 12 \\
\hline Vai ao estoque de consumíveis e pega parafusos; & 1.1 & 10 \\
\hline Vai a bancada; & 1.1 & 10 \\
\hline parafusa as madeiras na base de metal; & & 180 \\
\hline \multirow{2}{*}{ Pega o rolo de plástico bolha } & 1.14 & 19 \\
\hline & 1.14 & 19 \\
\hline joga no chão e corta & & 20 \\
\hline \multirow[t]{2}{*}{ Pede ajuda e coloca base no chão em cima do plástico bolha; } & 1.3 & 20 \\
\hline & 1.3 & 20 \\
\hline \multicolumn{3}{|l|}{ Finaliza parte de metal. } \\
\hline \multirow[t]{4}{*}{ Pega base de madeira e leva para bancada ( 2 viagens); } & 1.6 & 12 \\
\hline & 1.6 & 12 \\
\hline & 1.6 & 12 \\
\hline & 1.6 & 12 \\
\hline \multirow[t]{2}{*}{ Pega guias no estoque; } & 1.6 & 12 \\
\hline & 1.6 & 12 \\
\hline aumenta os furos das peças de madeira & & 30 \\
\hline \multirow[t]{2}{*}{ Vai ao estoque de consumíveis pegar peças; } & 1.1 & 10 \\
\hline & 1.1 & 10 \\
\hline \multirow[t]{2}{*}{ Pega parafusadeira e monta; } & 1.21 & 6 \\
\hline & 1.21 & 6 \\
\hline \multirow[t]{2}{*}{ Pede ajuda na estofaria para pegar o estofado no estoque; } & 1.13 & 23 \\
\hline & 1.13 & 23 \\
\hline \multirow{2}{*}{ Vai ao estoque de consumíveis pegar o resto das peças - monta; } & 1.1 & 10 \\
\hline & 1.1 & 10 \\
\hline monta laterais e estofado & & 195 \\
\hline \multirow[t]{2}{*}{ Pede ajuda para levar a base de mármore - testa; } & 1.3 & 20 \\
\hline & 1.3 & 20 \\
\hline
\end{tabular}




\begin{tabular}{|c|c|c|}
\hline Pede ajuda para colocar na base de metal; & & 15 \\
\hline \multirow[t]{2}{*}{ Pega peças faltantes no estoque de consumíveis - termina montagem (de joelhos); } & 1.1 & 10 \\
\hline & 1.1 & 10 \\
\hline \multirow[t]{3}{*}{ Pega bastão e embala conjunto em plástico bolha. } & 1.6 & 12 \\
\hline & 1.6 & 12 \\
\hline & $?$ & 150 \\
\hline \multirow[t]{4}{*}{ Pega a Fita adesiva para unir o bastão a embalagem, e fecha tudo com plastico bolha e fita } & 1.21 & 6 \\
\hline & 1.21 & 6 \\
\hline & 1.19 & 10 \\
\hline & 1.19 & 10 \\
\hline Vai até o estoque de componentes e pega o adesivo & 1.1 & 10 \\
\hline Volta ao posto & 1.1 & 10 \\
\hline Adesiva as duas laterais & & 15 \\
\hline
\end{tabular}

Adesiva as duas laterais

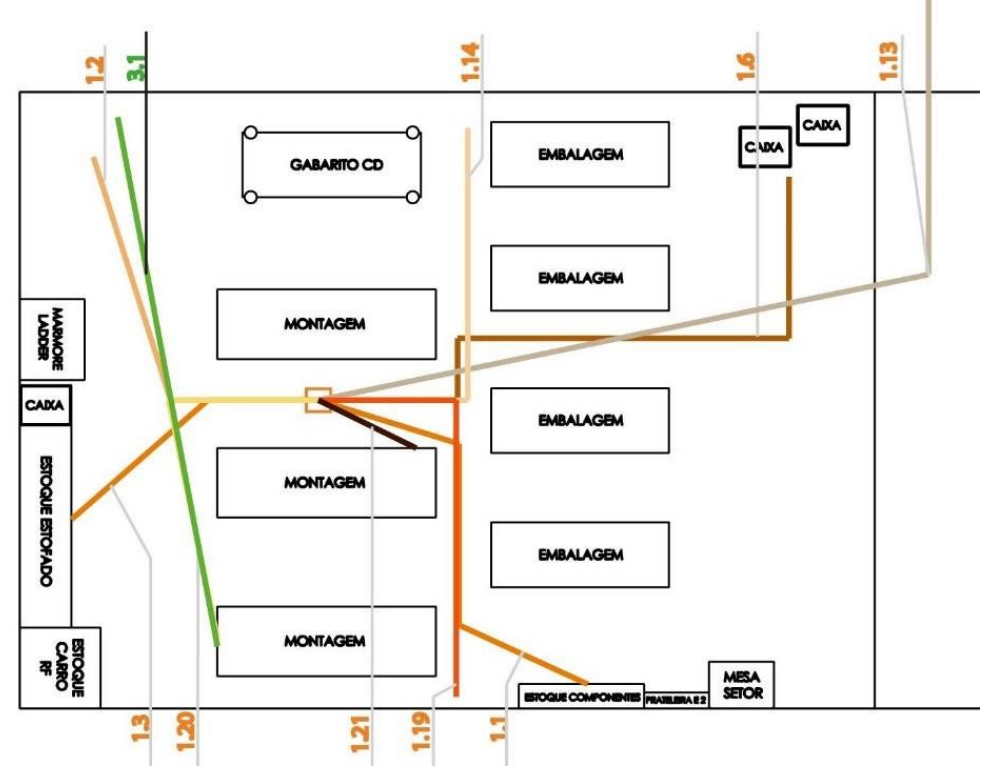

Figura III: Deslocamentos processo atual - Ladder Barrel

\section{Processo Montagem Step Chair}

\begin{tabular}{|c|c|c|}
\hline Ações & Deslocamento & Tempo (s) \\
\hline \multirow[t]{2}{*}{ Vai ao estoque pega base de metal - leva até a bancada da rebitadeira - rebita; } & 1.2 & 8 \\
\hline & 3.1 & 18 \\
\hline Troca o Bico & & 68 \\
\hline Rebita uma parte & & 50 \\
\hline Troca o Bico & & 60 \\
\hline Rebita outra parte & & 30 \\
\hline Leva a base a bancada; & 1.20 & 8 \\
\hline \multirow[t]{4}{*}{ Vai ao estoque pegar madeira pés e acessórios (2 viagens); } & 1.6 & 12 \\
\hline & 1.6 & 12 \\
\hline & 1.6 & 12 \\
\hline & 1.6 & 12 \\
\hline \multirow[t]{2}{*}{ Vai ao estoque de consumíveis e pega parafusos } & 1.1 & 10 \\
\hline & 1.1 & 10 \\
\hline Monta os pés da SC( mancais e acessorios - estofado) & & 240 \\
\hline \multirow[t]{2}{*}{ Vai ao estoque e pega o feltro da base de metal } & 1.1 & 10 \\
\hline & 1.1 & 10 \\
\hline Recorta e Cola o feltro na base & & 80 \\
\hline Começa a montar o eixo do pedal e termina a furação do pedal. & & 210 \\
\hline Começa a montar a regulagem de molas limpa e parafusa & & 70 \\
\hline \multirow{4}{*}{ Vai ao estoque pegar madeira laterais (2 viagens); } & 1.6 & 12 \\
\hline & 1.6 & 12 \\
\hline & 1.6 & 12 \\
\hline & 1.6 & 12 \\
\hline \multirow[t]{2}{*}{ Vai ao estoque de consumíveis e pega parafusos e Monta; } & 1.1 & 10 \\
\hline & 1.1 & 10 \\
\hline Monta Laterais encaixa os parafusos previamente & & 120 \\
\hline Vai até o estoque de estofados pega o assento e m & 1.3 & 5 \\
\hline
\end{tabular}




\begin{tabular}{|c|c|c|}
\hline & 1.3 & 5 \\
\hline Monta o assento & & 90 \\
\hline \multirow[t]{2}{*}{ Vai ao estoque e pega peças do mancal; } & 1.6 & 12 \\
\hline & 1.6 & 12 \\
\hline \multirow[t]{2}{*}{ Vai ao estoque de consumíveis e pega as buchas; } & 1.1 & 10 \\
\hline & 1.1 & 10 \\
\hline passa o macho; & & 80 \\
\hline Pega o macho na caixa de ferramentas - passa o macho; & 1.21 & 6 \\
\hline 20 segundos para cada se nada acontecer & 1.21 & 6 \\
\hline Monta o mancal lateral na lateral de madeira & & 120 \\
\hline \multirow[t]{2}{*}{ Vai ao estoque de estofados e pega os pés e monta; } & 1.3 & 5 \\
\hline & 1.3 & 5 \\
\hline Monta os estofados dos pedais ( $35 \mathrm{~s}$ cada) & & 70 \\
\hline \multirow[t]{2}{*}{ Pega papel ondulado e embala os pés; } & 1.15 & 8 \\
\hline & 1.15 & 8 \\
\hline Recorta o papel ondulado & & 25 \\
\hline \multirow[t]{2}{*}{ Pega plástico bolha; } & 1.14 & 19 \\
\hline & 1.14 & 19 \\
\hline \multirow[t]{4}{*}{ Pede ajuda e termina a embalagem no chão. } & 1.3 & 5 \\
\hline & 1.3 & 5 \\
\hline & 1.21 & 6 \\
\hline & 1.21 & 6 \\
\hline Vai até o estoque de componentes e pega o adesivo & 1.1 & 10 \\
\hline Volta ao posto & 1.1 & 10 \\
\hline Adesiva as duas laterais & & 15 \\
\hline
\end{tabular}

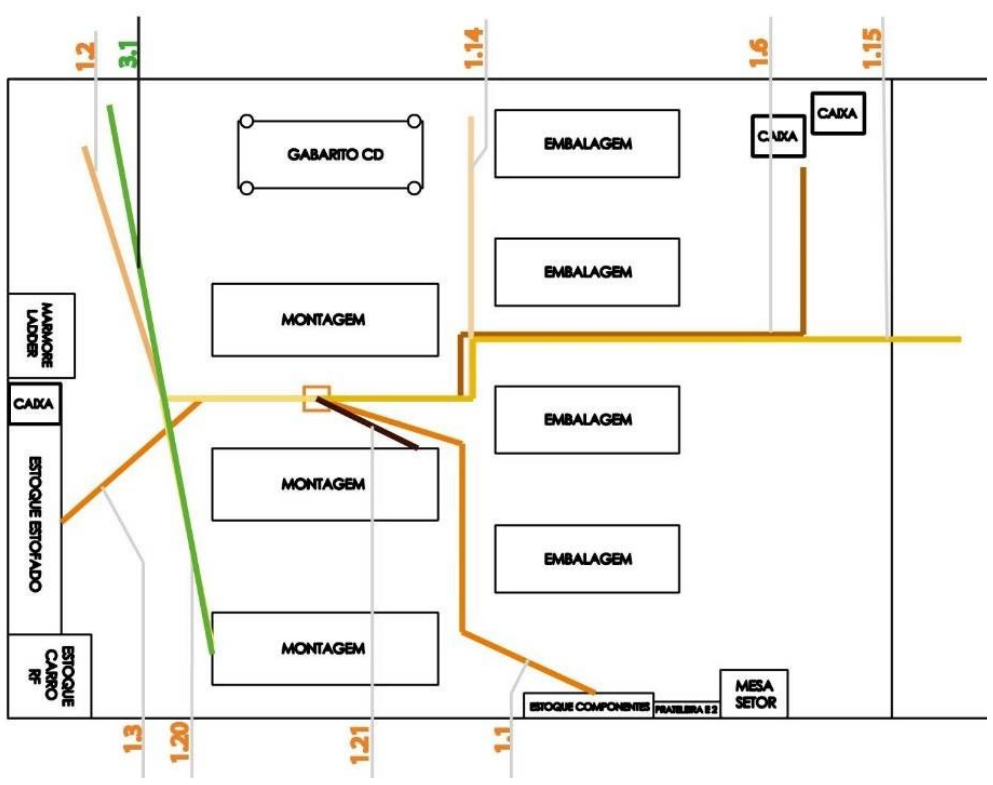

Figura IV: Deslocamentos processo atual - Step Chair.

\section{Apêndice B}

Neste tópico são apresentados os processos de montagem propostos para os equipamentos e o deslocamento aproximado. Os deslocamentos envolvidos no processo de montagem também são mostrados graficamente.

Proposta de processo montagem Cadilac

\begin{tabular}{|l|l|l|l|}
\hline Ponto partida & Atividade/ deslocamento & Cod. & Distância \\
\hline Posto & Pega o carrinho e vai até o estoque de consumíveis & 1.1 & 7,525 \\
\hline & Pega material necessário para montagem & & \\
\hline Est. Consumiveis & vai a bancada de embalagens & 2.1 & 3,866 \\
\hline & deixa o carrinho & & \\
\hline Bancada Embal. & vai até o estoque madeiras CD/RF pega o cavalete & 3.1 & 3,089 \\
\hline Est. M. DC/RF & Vai a área dos cavaletes & 4.1 & 2,564 \\
\hline & prepara os cavaletes & & \\
\hline Cavaletes & pede ajuda para pegar estofado CD & 4.1 & 2,564 \\
\hline
\end{tabular}




\begin{tabular}{|c|c|c|c|}
\hline Est. M. DC/RF & leva até os cavaletes & 4.1 & 2,564 \\
\hline Cavaletes & pede ajuda para pegar base $\mathrm{CD}$ & 4.1 & 2,564 \\
\hline \multirow[t]{2}{*}{ Est. M. DC/RF } & leva até os cavaletes & 4.1 & 2,564 \\
\hline & monta base & & \\
\hline Cavaletes & busca a caixa e divisória de papelão & 4.2 & 4,749 \\
\hline \multirow[t]{2}{*}{ est. Caixas } & $\begin{array}{l}\text { vai a bancada embalagem monta a caixa - material necessário no carrinho - e } \\
\text { divisória, deixa na bancada }\end{array}$ & 3.2 & 5,8 \\
\hline & Forra caixa com plastico bolha (rolo sempre no área) & & \\
\hline Bancada Embal. & pede ajuda e pega a base nos cavaletes & 3.3 & 2,78 \\
\hline Cavaletes & coloca a base na embalagem & 3.3 & 2,78 \\
\hline Bancada Embal. & pega carrinho vai ao estoque de metais & 3.4 & 6,387 \\
\hline \multirow{2}{*}{ Est. Metais } & pega metais e leva para bancada de rebite & 2.4 & 2,025 \\
\hline & Rebita & & \\
\hline \multirow[t]{2}{*}{ B. rebite } & leva para a bancada de montagem & 1.3 & 6,855 \\
\hline & deixa as peças e carrinho & & \\
\hline Posto & vai ao estoque de metais e busca as laterais superiores & 1.3 & 6,855 \\
\hline \multirow[t]{2}{*}{ Est. Metais } & vai a bancada & 1.3 & 6,855 \\
\hline & monta a parte superior eo restante necessário & & \\
\hline posto & Vai ao estoque de metais e pega o inox lateral & 1.3 & 6,855 \\
\hline Est. Metais & leva peças para o gabarito & 2.5 & 8,057 \\
\hline Gabarito & Est. Metais & 2.5 & 8,057 \\
\hline Est. Metais & leva peças para o gabarito e o carrinho & 2.5 & 8,057 \\
\hline Gabarito & Est. Metais & 2.5 & 8,057 \\
\hline Est. Metais & volta para a bancada & 1.3 & 6,855 \\
\hline \multirow{3}{*}{\begin{tabular}{|l|} 
Posto \\
\end{tabular}} & pede ajuda e leva a parte superior para o gabarito & 1.4 & 6,984 \\
\hline & Monta, testa e lubrifica & & \\
\hline & desmonta & & \\
\hline \multirow[t]{2}{*}{ Gabarito } & pede ajuda e leva para bancada & 1.4 & 6,984 \\
\hline & desmonta parte superior e embala & & \\
\hline posto & leva pra embalagem & 1.5 & 6,248 \\
\hline Bancada Embal. & Posto & 1.5 & 6,248 \\
\hline posto & leva pra embalagem & 1.5 & 6,248 \\
\hline Bancada Embal. & Pega peças no gabarito & 3.5 & 0,942 \\
\hline Gabarito & embala peças & 3.5 & 0,942 \\
\hline Bancada Embal. & Pega peças no gabarito & 3.5 & 0,942 \\
\hline Gabarito & embala peças & 3.5 & 0,942 \\
\hline Bancada Embal. & Pega peças no gabarito & 3.5 & 0,942 \\
\hline Gabarito & embala peças & 3.5 & 0,942 \\
\hline Bancada Embal. & Pega peças no gabarito & 3.5 & 0,942 \\
\hline \multirow[t]{3}{*}{ Gabarito } & embala peças & 3.5 & 0,942 \\
\hline & coloca itens restantes & & \\
\hline & Fecha a embalagem & & 7,76 \\
\hline
\end{tabular}

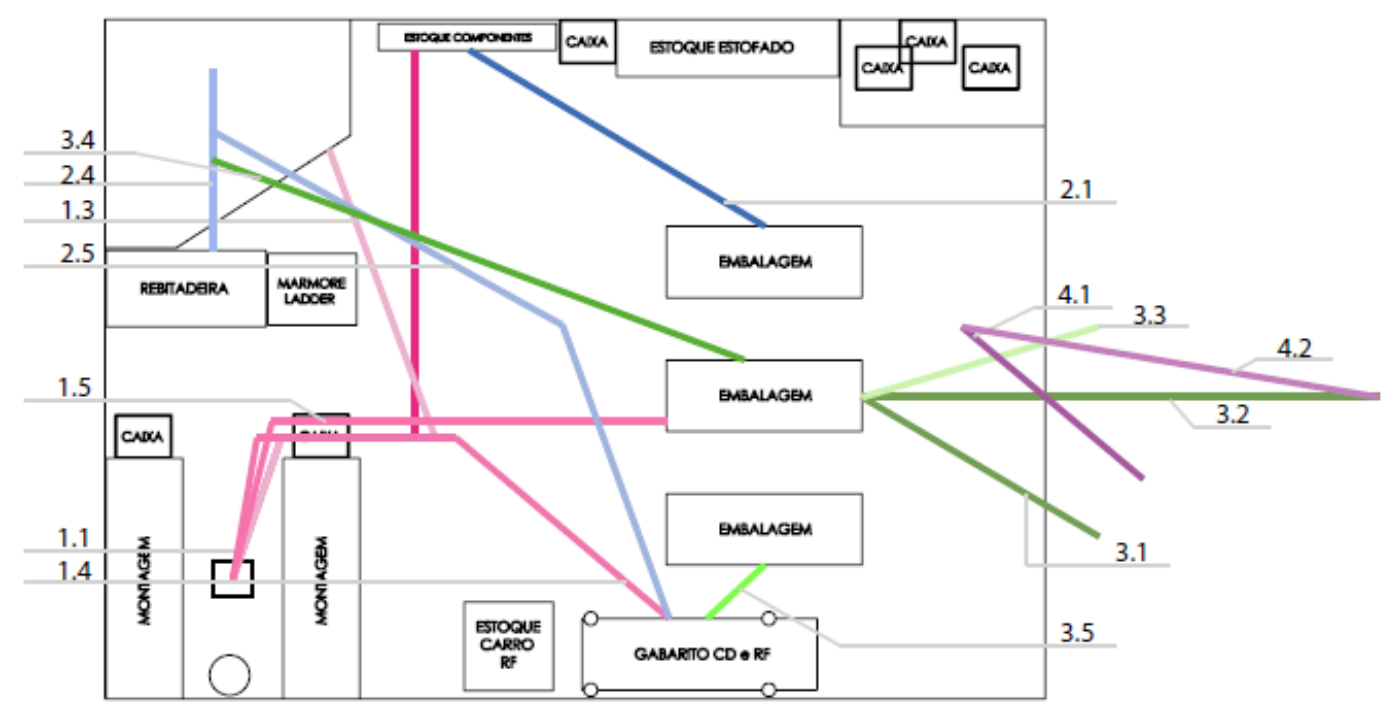

Figura V: Deslocamentos processo proposto - Cadilac. 
Proposta de processo montagem Reformer

\begin{tabular}{|c|c|c|c|}
\hline Ponto partida & Atividade/ deslocamento & Cod. & Distância \\
\hline \multirow[t]{2}{*}{ Posto } & Pega o carrinho e vai até o estoque almoxarifado & 1.6 & 9,203 \\
\hline & pega caixa das peças RF & & \\
\hline \multirow[t]{2}{*}{ Est. Almox } & vai ao etoque de estofados & 2.3 & 2,3 \\
\hline & pega estofados necessários & & \\
\hline \multirow[t]{2}{*}{ Est. Estofados } & vai ao estoque de consumíveis & 2.2 & 3,957 \\
\hline & pega material necessário & & \\
\hline \multirow[t]{2}{*}{ Est. Consumíveis } & leva carrinho para o posto & 1.1 & 7,525 \\
\hline & monta o carrinho e demais acessórios & & \\
\hline Posto & Leva carrinho RF para o estoque de Carrinho & 1.7 & 5,194 \\
\hline Est. Car. & pede ajuda e busca base RF & 2.6 & 6,698 \\
\hline \multirow[t]{4}{*}{ Est.M. DC/RF } & leva base ao posto & 1.8 & 10,869 \\
\hline & monta trilho base & & \\
\hline & pede ajuda e vira & & \\
\hline & monta outro lado & & \\
\hline \multirow[t]{2}{*}{ Posto } & vai a bancada de embalagens & 1.5 & 6,248 \\
\hline & deixa o carrinho & & \\
\hline Bancada Embal. & vai até o estoque madeiras CD/RF pega o cavalete & 3.1 & 3,089 \\
\hline \multirow[t]{2}{*}{ Est. M. DC/RF } & Vai a área dos cavaletes & 4.1 & 2,564 \\
\hline & prepara os cavaletes & & \\
\hline Cavaletes & Vai ao posto & 1.9 & 11,553 \\
\hline posto & pede ajuda para levar base ao cavalete & 1.9 & 11,553 \\
\hline Cavaletes & busca carrinho no estoque & 4.3 & 8,273 \\
\hline \multirow[t]{2}{*}{ Est. Car. } & coloca carrinho na base & 4.3 & 8,273 \\
\hline & monta e testa & & \\
\hline Cavaletes & busca a caixa e divisória de papelão & 4.2 & 4,749 \\
\hline \multirow[t]{2}{*}{ est. Caixas } & $\begin{array}{l}\text { vai a bancada embalagem monta a caixa - material necessário no carrinho - e } \\
\text { divisória, deixa na bancada }\end{array}$ & 3.2 & 5,8 \\
\hline & Forra caixa com plastico bolha (rolo sempre no área) & & \\
\hline Bancada Embal. & pede ajuda e pega a base nos cavaletes & 3.3 & 2,78 \\
\hline \multirow[t]{3}{*}{ Cavaletes } & coloca a base na embalagem & 3.3 & 2,78 \\
\hline & embala o restante das peças e acessórios & & \\
\hline & fecha a caixa & & 7,76 \\
\hline
\end{tabular}

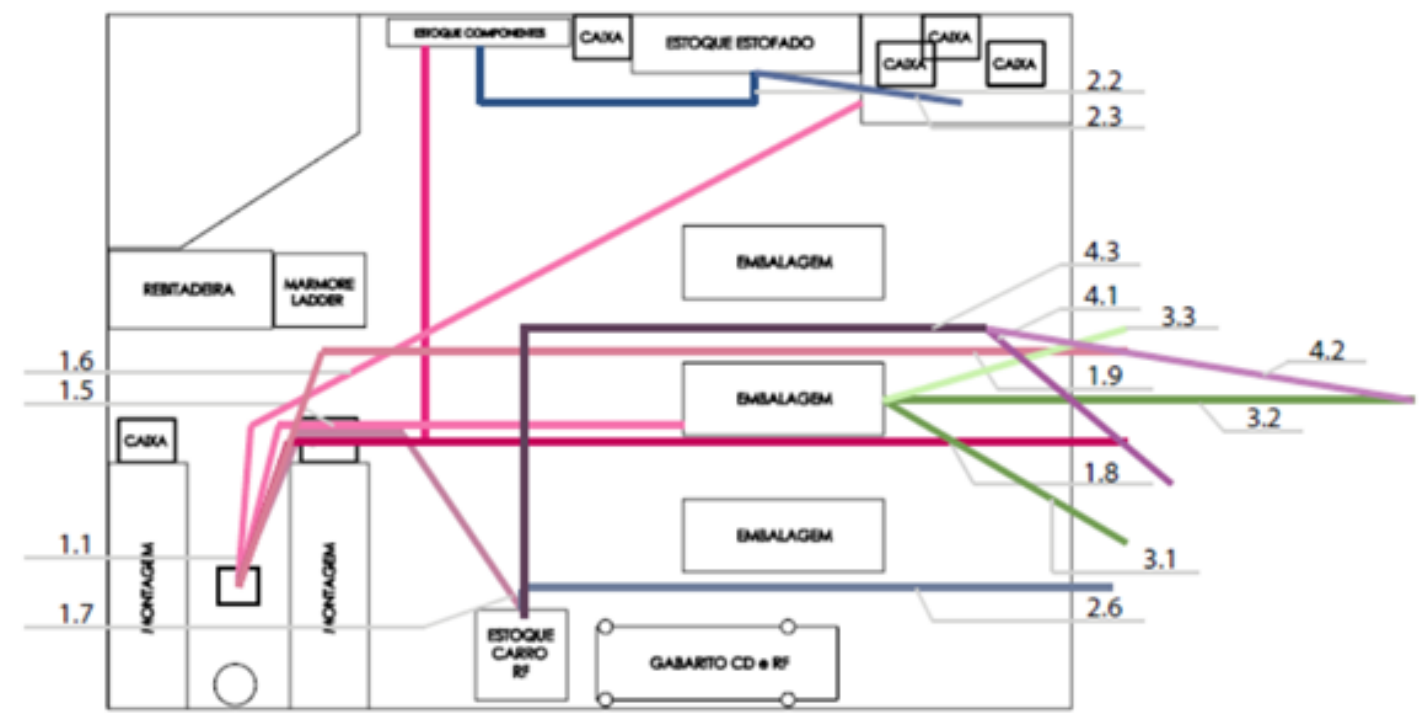

Figura VI: Deslocamentos processo sugerido - Reformer

Proposta de processo montagem Ladder Barrel

\begin{tabular}{|l|l|l|l|}
\hline Ponto partida & Atividade/ deslocamento & Cod. & Distância \\
\hline Posto & Pega o carrinho e vai até o estoque almoxarifado & 1.6 & \\
\hline & pega caixa das peças & & \\
\hline Est. Almox & vai ao estoque de estofados & 2.3 & \\
\hline & pega estofados necessários & 2,3 \\
\hline Est. Estofados & vai ao estoque de consumíveis & & \\
\hline & pega material necessário & 3,2 & \\
\hline Est. Consumíveis & leva carrinho para o posto & & \\
\hline Posto & vai para o estoque de metais & 1.1 & \\
\hline
\end{tabular}




\begin{tabular}{|c|c|c|c|}
\hline & pega base metal & & \\
\hline \multirow[t]{2}{*}{ Est. Metais } & leva para bancada rebite & 2.4 & 2,025 \\
\hline & Rebita & & \\
\hline \multirow[t]{2}{*}{ B. Rebite } & vai para o posto & 1.2 & 2,829 \\
\hline & monta as partes & & \\
\hline \multirow[t]{2}{*}{ posto } & pede ajuda e leva a base de mármore & 1.10 & 2,941 \\
\hline & Ajusta & & \\
\hline \multirow[t]{2}{*}{ B. mármore } & vai até área de embalagem & 3.6 & 3,688 \\
\hline & estende plástico bolha & & \\
\hline B. Embalagem & vai ao posto e pede ajuda & 1.5 & 6,248 \\
\hline posto & leva base para embalagem & 1.5 & 6,248 \\
\hline B. Embalagem & volta para o posto & 1.5 & 6,248 \\
\hline \multirow[t]{3}{*}{ posto } & leva barril para embalagem & 1.5 & 6,248 \\
\hline & termina montagem & & \\
\hline & finaliza embalagem & & \\
\hline
\end{tabular}

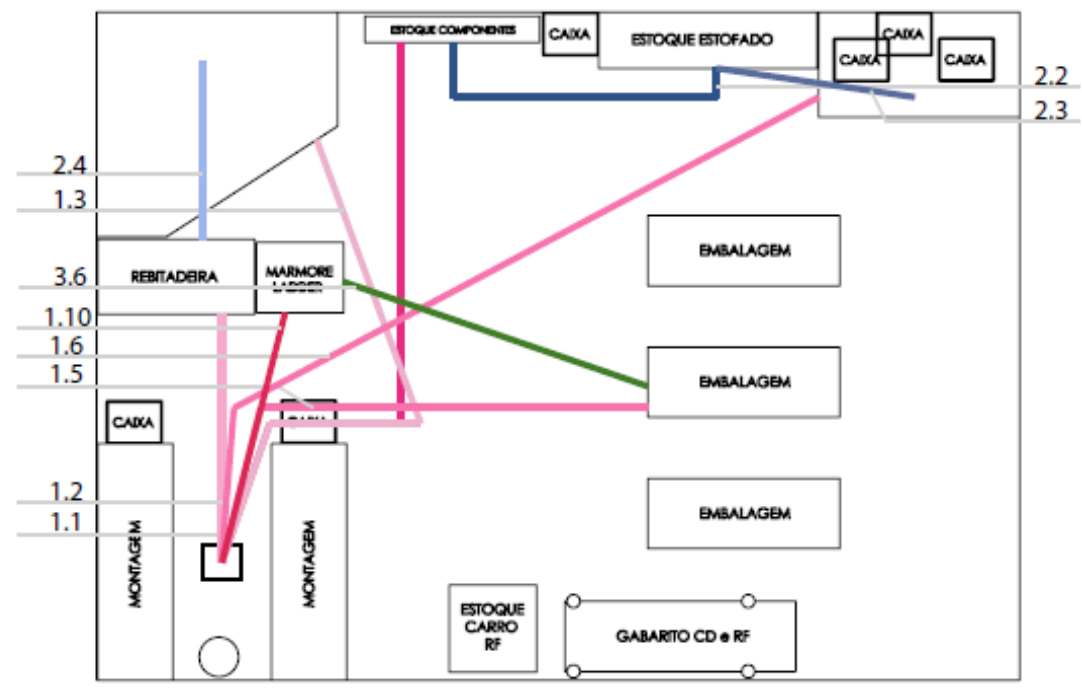

Figura VII: Deslocamentos processo proposto - Ladder Barrel.

Proposta de processo montagem Step Chair

\begin{tabular}{|l|l|l|l|}
\hline Ponto partida & Atividade/ deslocamento & Cod. & Distância \\
\hline Posto & Pega o carrinho e vai até o estoque almoxarifado & 1.6 & 9,203 \\
\hline & pega caixa das peças & & \\
\hline Est. Almox & vai ao estoque de estofados & 2.3 & 2,3 \\
\hline & pega estofados necessários & & \\
\hline Est. Estofados & vai ao estoque de consumíveis & 2.2 & 3,957 \\
\hline & pega material necessário & 1.1 & 7,525 \\
\hline Est. Consumíveis & leva carrinho para o posto & 1.3 & 6,855 \\
\hline Posto & vai para o estoque de metais & & \\
\hline & pega base metal & 2.4 & 2,025 \\
\hline Est. Metais & leva para bancada rebite & & \\
\hline & Rebita & 1.2 & 2,829 \\
\hline B. Rebite & vai para o posto & & \\
\hline & monta as partes & 1.5 & 6,248 \\
\hline Posto & vai a área de embalagem & & \\
\hline & estende plastico bolha & 1.5 & 6,248 \\
\hline B. Embalagem & volta ao posto & 1.5 & 6,248 \\
\hline Posto & pede ajuda e leva para a embalagem & & \\
\hline & Finaliza embalagem & & \\
\hline
\end{tabular}




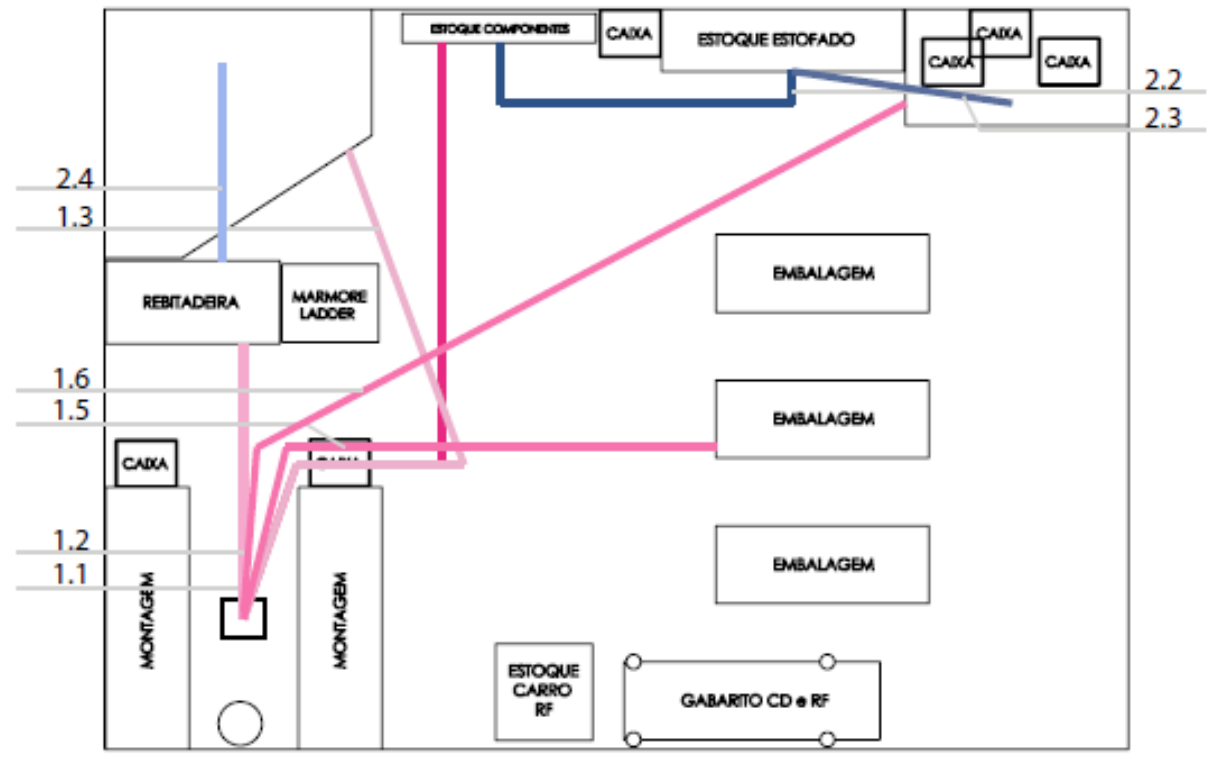

Figura VIII: Deslocamentos processo proposto - Step Chair. 